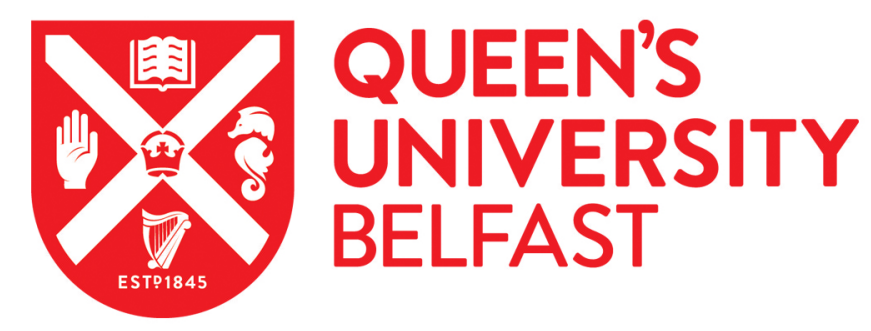

\title{
Effects of slag substitution on physical and mechanical properties of fly ash-based alkali activated binders (AABs)
}

Rafeet, A. M., Vinai, R., Soutsos, M., \& Sha, W. (2019). Effects of slag substitution on physical and mechanical properties of fly ash-based alkali activated binders (AABs). Cement and Concrete Research, 122, 118-135. https://doi.org/10.1016/j.cemconres.2019.05.003

Published in:

Cement and Concrete Research

Document Version:

Peer reviewed version

Queen's University Belfast - Research Portal:

Link to publication record in Queen's University Belfast Research Portal

Publisher rights

(c) 2019 Elsevier Ltd.

This manuscript version is made available under the CC-BY-NC-ND 4.0 license http://creativecommons.org/licenses/by-nc-nd/4.0/,which permits distribution and reproduction for non-commercial purposes, provided the author and source are cited.

\section{General rights}

Copyright for the publications made accessible via the Queen's University Belfast Research Portal is retained by the author(s) and / or other copyright owners and it is a condition of accessing these publications that users recognise and abide by the legal requirements associated with these rights.

Take down policy

The Research Portal is Queen's institutional repository that provides access to Queen's research output. Every effort has been made to ensure that content in the Research Portal does not infringe any person's rights, or applicable UK laws. If you discover content in the Research Portal that you believe breaches copyright or violates any law, please contact openaccess@qub.ac.uk. 


\title{
Effects of slag substitution on physical and mechanical properties of fly ash-based alkali activated binders (AABs).
}

\author{
Ali Rafeet, Raffaele Vinai*, Marios Soutsos, and Wei Sha \\ School of Natural and Built Environment, Queen’s University Belfast, BT9 5AG, United Kingdom \\ *Corresponding author. Current address: College of Engineering, Mathematics and Physical Sciences, \\ University of Exeter, email: r.vinai@exeter.ac.uk, tel. +44 (0)1392 723627
}

\begin{abstract}
Neat fly ash-based alkali activated binders require high activator dosages and high temperature curing in order to develop satisfactory mechanical properties. Blending ground granulated blast furnace slag (GGBS) with fly ash can give medium to high strengths without the need for high temperature oven curing. An extensive investigation was carried out for understanding the effects of GGBS substitution of fly ash in mortar. GGBS substitution in the mix has an impact on mix proportions, fresh and hardened properties, and microstructure of reaction products. The strength of fly ash/GGBS blends cured at room temperature increased with the increase of GGBS content, whilst setting time showed an opposite trend. Fly ash/GGBS blends required lower activator dosages for obtaining high compressive strength, which has cost and environmental benefits. XRD, FTIR, TGA, and SEM/EDX results confirmed the presence of C-A-S-H gel as a reaction product with as low as $20 \%$ GGBS content.
\end{abstract}

Keywords: alkali activated cement (D), microstructure (B), mixture proportioning (A), fly ash (D), Granulated Blast-Furnace Slag (D).

\section{Introduction}

Alkali activated concrete (AAC) can be a potential alternative to ordinary Portland cement based concrete (OPC) for reducing the $\mathrm{CO}_{2}$ emissions from the building sector, which account for around $8 \%$ of the worldwide carbon emissions [1]. Numerous studies have been carried out worldwide on binders based on neat fly ash or neat slag. Low calcium fly ash-based binders usually require high temperature curing and high activator dosages to achieve good mechanical properties. Chemical activators are responsible for the majority of $\mathrm{CO}_{2}$ emissions and production costs of AAC, as using high activator dosages leads to an increase in both of these [2]. This may hinder the industrial uptake of this technology. Slag-based binders, on the other hand, require relatively lower activator dosages but suffer from some technical problems such as rapid setting and low workability. Recently, blended 
binders have attracted a great deal of attention mainly due to their potential to mitigate some of the above mentioned issues.

Blending fly ash and Ground Granulated Blast Furnace Slag (GGBS) enables curing at ambient temperature (20 ${ }^{\circ} \mathrm{C}$ ) leading to a denser and more compact microstructure and therefore better mechanical properties [3]. However, despite around 40 years of studying [4], relatively few investigations focused on the optimization of mix design in terms of binder blends and their influence on activator dosage, fresh and hardened properties of the mix and identification of the microstructure of reaction products. The majority of the studies focused on pastes $[5,6]$ and only few data are available on the properties of blended fly ash/GGBS mortars and concrete [7-9]. The main conclusions from these studies were that the substitution of GGBS increased the compressive strength but decreased the setting time especially when higher percentages of GGBS and higher chemical dosages were used. Understanding the chemistry of AAC can also help towards designing more robust and durable concrete. However, the reaction mechanism of fly ash, despite having been studied for decades, is still not yet well understood [1]. Blending fly ash with GGBS makes the reaction process more complex as different reaction products can form. These reaction products depend on the ratio of slag and the activation dosages. Geopolymer gel (N-A-S-H) was found to be the main reaction product in mixes with slag ratio up to $25 \%$, with possible formation of zeolites when this ratio was further decreased [10].

This study aims to provide more insight into the influence of GGBS substitution on (a) the physical and mechanical properties of fly ash/GGBS blends, (b) the required activator dosage and (c) heat output development. Furthermore, characterisation of reaction products was carried out using microstructural techniques in order to understand the influence of slag content on the microstructure of the matrix.

\section{Materials and Methods}

The binders used in this study were based on fly ash and GGBS having chemical compositions (obtained by Xray fluorescence $-\mathrm{XRF}$ ) as shown in Table 1. Fly ash was supplied by Power Minerals Ltd, United Kingdom. It was class F according to ASTM C618 [11], and compliant to BS EN 450 standard [12], with Loss on Ignition (LOI) falling into Category A. GGBS was supplied by Civil and Marine Ltd, United Kingdom. The slag was defined as basic since its basicity coefficient $\mathrm{K}_{\mathrm{b}}=(\mathrm{CaO}+\mathrm{MgO}) /\left(\mathrm{SiO}_{2}+\mathrm{Al}_{2} \mathrm{O}_{3}\right)$ was higher than 1 . The physical properties of the precursors are shown in Table 2. The grain size distribution is described by the parameters $\mathrm{D}_{50}$ and $\mathrm{D}_{90}$, i.e. the mesh sizes for $50 \%$ and $90 \%$ sample mass passing respectively.

Oven-dried natural siliceous sand having grain size in the range 0 to $4 \mathrm{~mm}$ and density $2.69 \mathrm{~g} / \mathrm{cm}^{3}$ was used for the preparation of the mortars. 
Table 1. Main oxides determined by XRF analysis on precursor materials.

\begin{tabular}{cccccccccccc}
\hline Oxide & $\mathrm{CaO}$ & $\mathrm{SiO}_{2}$ & $\mathrm{Al}_{2} \mathrm{O}_{3}$ & $\mathrm{Fe}_{2} \mathrm{O}_{3}$ & $\mathrm{Na}_{2} \mathrm{O}$ & $\mathrm{K}_{2} \mathrm{O}$ & $\mathrm{SO}_{3}$ & $\mathrm{MgO}$ & $\mathrm{TiO}_{2}$ & $\begin{array}{c}\text { Other oxides } \\
\text { (minors) }\end{array}$ & $\mathrm{LOI}$ \\
\hline Fly ash & 2.2 & 46.8 & 22.5 & 9.2 & 0.9 & 4.1 & 0.9 & 1.3 & 1.1 & 7.4 & 3.6 \\
GGBS & 43.7 & 29.4 & 11.2 & 0.4 & 1.0 & 0.9 & 1.8 & 6.9 & 0.7 & 1.6 & 2.4 \\
\hline
\end{tabular}

Table 2. Physical properties of precursor materials.

\begin{tabular}{cccccc}
\hline Property & $\begin{array}{c}\text { Particle density } \\
\left(\mathbf{g} / \mathbf{c m}^{\mathbf{3}}\right)\end{array}$ & $\begin{array}{c}\text { Grain size } \\
\text { range }(\boldsymbol{\mu m})\end{array}$ & $\mathbf{D}_{\mathbf{5 0}}(\boldsymbol{\mu m})$ & $\mathbf{D}_{\mathbf{9 0}}(\boldsymbol{\mu m})$ & $\begin{array}{c}\text { Amorphous } \\
\text { content }(\%)\end{array}$ \\
\hline Fly ash & 2.42 & $0.24-105$ & 16.8 & 59.1 & 86 \\
GGBS & 2.92 & $0.24-149$ & 14.4 & 47.0 & $>95$ \\
\hline
\end{tabular}

Alkali dosage $(\mathrm{M}+)$ and alkali modulus $(\mathrm{AM})$ were the parameters adopted for determining the activator dosage (i.e. mass of sodium hydroxide and sodium silicate solutions in the mix). $\mathrm{M}+$ is the mass ratio of sodium oxide $\left(\mathrm{Na}_{2} \mathrm{O}\right)$ to the total mass of the precursor, whilst $\mathrm{AM}$ is the mass ratio of $\mathrm{Na}_{2} \mathrm{O}$ to $\mathrm{SiO}_{2}$. The activators used in this study were commercial grade ( $99 \%$ purity) sodium hydroxide $(\mathrm{NaOH})$, and sodium silicate solution with $\mathrm{SiO}_{2}: \mathrm{Na}_{2} \mathrm{O}$ mass ratio $=2: 1$ (mass composition: $\mathrm{Na}_{2} \mathrm{O} 12.8 \%, \mathrm{SiO}_{2} 25.5 \%$, water $61.7 \%$ ), provided by Fisher Scientific UK. $\mathrm{NaOH}$ solutions with the required concentration were prepared by dissolving $\mathrm{NaOH}$ prills in tap water, leaving the solution to cool down for at least 24 hours before use. Sodium hydroxide solution was used to adjust the $\mathrm{Na}_{2} \mathrm{O}$ content in the activating solution in order to achieve the required $\mathrm{M}+$. The water-to-solid ratio (w/s) was defined as the mass ratio of water to the mass of binder including the solid chemicals (i.e. mass of precursor + mass of $\mathrm{SiO}_{2}$ and $\left.\mathrm{Na}_{2} \mathrm{O}\right)$.

Mortars were mixed in a planetary mixer. The sand/binder ratio was kept constant at 2.75. Dry constituents (sand, fly ash and GGBS) were first dry mixed for 2 minutes, then the liquid part was added and mixing continued for a further 5 minutes. Typical mix proportions of mortars are shown in Tables $3 \mathrm{a}$ for production batches. These have been converted to grams/litre, see Table $3 b$.

Table 3a. Typical mix proportions for mortar production batch $(\mathrm{M}+7.5 \%$, AM 1.25, w/s ratio 0.37).

\begin{tabular}{lcccccc}
\hline Label & Fly ash (g) & GGBS (g) & $\begin{array}{c}\text { NaOH solution } \\
\text { a } \mathbf{3 0 \%} \text { conc. }(\mathbf{g})\end{array}$ & $\begin{array}{c}\text { Sodium silicate } \\
\text { solution }(\mathbf{g})\end{array}$ & $\begin{array}{c}\text { Water } \\
\text { (g) }\end{array}$ & Sand (g) \\
\hline $\mathbf{1 0 0} / \mathbf{0}$ & & & 97 & 118 & 70 & 1375 \\
$\mathbf{9 5 / 5}$ & 400 & 0 & 97 & 118 & 70 & 1375 \\
$\mathbf{8 0} / \mathbf{2 0}$ & 400 & 100 & 97 & 118 & 70 & 1375 \\
$\mathbf{6 0} / \mathbf{4 0}$ & 300 & 200 & 97 & 118 & 70 & 1375 \\
$\mathbf{3 0} / \mathbf{7 0}$ & 150 & 350 & 97 & 118 & 70 & 1375 \\
\hline
\end{tabular}


Table 3b. Typical mix proportions for 1 litre of mortar (M+ 7.5\%, AM 1.25, w/s ratio 0.37 ).

\begin{tabular}{lcccccc}
\hline Label & Fly ash (g) & GGBS (g) & $\begin{array}{c}\text { NaOH solution } \\
\text { a } \mathbf{3 0 \%} \text { conc. }(g)\end{array}$ & $\begin{array}{c}\text { Sodium silicate } \\
\text { solution }(\mathbf{g})\end{array}$ & $\begin{array}{c}\text { Water } \\
(\mathbf{g})\end{array}$ & Sand (g) \\
\hline $\mathbf{1 0 0 / 0}$ & 530 & 0 & 102 & 125 & 74 & 1456 \\
$\mathbf{9 5 / 5}$ & 504 & 26 & 102 & 125 & 74 & 1459 \\
$\mathbf{8 0 / 2 0}$ & 427 & 107 & 103 & 126 & 74 & 1467 \\
$\mathbf{6 0 / 4 0}$ & 323 & 215 & 104 & 127 & 75 & 1478 \\
$\mathbf{3 0 / 7 0}$ & 163 & 381 & 105 & 128 & 76 & 1495 \\
\hline
\end{tabular}

- Setting time was measured with a manual Vicat apparatus. The paste consistency required for this method was not achievable with geopolymer pastes due to the need of higher water contents for preventing quick reaction as discussed by Vinai et al. [13]. The Vicat method was instead used with mortars for comparing the effects of different binder blends.

- The consistency of mortars was assessed using the flow table in accordance with British Standard BS EN 1015-3: 1999. The conical frustum available in the laboratory had different dimensions than the standard $(90 \mathrm{~mm}$ instead of $60 \mathrm{~mm}$ in height, internal diameter $65 \mathrm{~mm}$ instead of $100 \mathrm{~mm}$ at the base and $40 \mathrm{~mm}$ instead of $70 \mathrm{~mm}$ at the top).

- 50-mm mortar cube specimens were cast in PVC moulds and compacted on a vibrating table. Moulds were then wrapped in a plastic film and stored for curing. Neat fly ash samples were oven cured at $70{ }^{\circ} \mathrm{C}$ whereas fly ash/GGBS blends were cured at a constant room temperature of $20{ }^{\circ} \mathrm{C} \pm 2{ }^{\circ} \mathrm{C}$ and a relative humidity of $55 \% \pm 5 \%$ until the day of testing. Samples were demoulded after 24 hours and tested for compressive strength at 1,7 and 28 days using a $2000 \mathrm{kN}$ capacity compression testing machine with a loading rate of $1.5 \mathrm{kN} / \mathrm{s}$, which is within the range specified in BS 12390-3: 2009.

- A TAM Air Isothermal Calorimetre (IC) was used for determining the heat of reaction of fly ash/GGBS paste blends. Ex-situ (i.e. sample mixed outside the machine and then lowered into the measuring chamber) and in-situ (i.e. sample mixed directly in the measuring chamber) methods were adopted. Exsitu measurements were carried out at two temperatures, i.e. 20 and $70{ }^{\circ} \mathrm{C}$, whilst for in-situ measurement one temperature, i.e. $20^{\circ} \mathrm{C}$, was applied.

X-ray diffraction (XRD), Fourier transform infrared spectroscopy (FTIR), thermo-gravimetric analysis (TGA) and scanning electron microscopy (SEM) coupled with Energy Dispersive X-ray analysis (EDX) techniques were used for the microstructural characterisation on paste samples:

- XRD was used to detect the crystal phases of both the raw materials and the reacted samples. Tests were carried out with a PANalytical X'Pert PRO diffractometer using pure copper-K-Alpha 1 radiation with 
wavelength $1.54 \AA$. The X-ray generator was set to $40 \mathrm{kV}$ and $40 \mathrm{~mA}$, the recorded angular range was 5 to $60^{\circ}(2 \theta)$ with a step close to $0.017^{\circ}$. Malvern PANalytical X'Pert Highscore Plus software was used for pattern interpretation. An internal standard (corundum) was used with raw fly ash for the quantification of mineralogical phases.

- $\quad$ FTIR spectra were obtained using a Jasco 4100 series FTIR Spectrometer to determine the chemical functional groups of raw materials and reacted samples. Jasco software was used for data interpretation. Attenuated Total Reflectance (ATR) attachment (germanium crystal) in the range $3960-650 \mathrm{~cm}^{-1}$ was measured, with a data interval $0.964 \mathrm{~cm}^{-1}$.

- TGA was performed using a thermobalance Netzsch TG 209 F1 Libra. Powder was obtained from the samples with the use of a mortar and pestle. The powder was placed in an alumina crucible and then heated from 25 to $1000{ }^{\circ} \mathrm{C}$ at $20^{\circ} \mathrm{C} / \mathrm{min}$ in an inert environment. The thermobalance was coupled with a Pfeiffer mass spectrometer Vacuum Thermostat for the analysis of gases emitted during the heating process.

- SEM images and EDX data were obtained on gold-palladium coated cubes of $1 \times 1 \times 1 \mathrm{~cm}$ with a FEI QUANTA 200 scanning electron microscope. The accelerating voltage was set at $20 \mathrm{kV}$. Six samples were analysed for each investigated mix.

\section{Results and discussion}

The effect of partially replacing fly ash with GGBS on the (a) fresh and hardened properties of mortars, (b) reaction heat development and (c) microstructure of pastes was investigated. A detailed study was carried out for evaluating the effect of activator dosage on neat fly ash mortars and fly ash/GGBS blends with high level of GGBS substitution $(70 \%$ in mass), in order to determine ranges of dosage giving high compressive strengths. Several microstructural analysis techniques were used to assess the properties of the reaction products and relate these to the compressive strengths of mortars. The chemical composition of reaction products was determined which gave an indication of the nature of the binding gel.

\subsection{Fresh and hardened properties of mixes with neat fly ash and fly ash/GGBS blends}

A first series of mixes aimed at assessing the effects of the GGBS inclusion in fly ash-based mortars cured at ambient temperature. This included tests for consistency, setting time and compressive strength. Samples were mixed with GGBS contents ranging from $5 \%$ by mass ( $5 \%$ GGBS and $95 \%$ fly ash, referred as to $95 / 5$, where the first number corresponds to the fly ash content and the second to the GGBS content) to 70\% (i.e. 30/70). Mixes with higher GGBS content exhibited setting within a very short time (i.e. less than 5 minutes) and therefore were 
not investigated. Water-to-solid ratio (w/s) was kept constant at 0.37 . Activator dosages were kept constant at $\mathrm{M}+$ $=7.5 \%$ and $\mathrm{AM}=1.25$, as suggested in a previous work [14].

\subsubsection{Fresh properties of fly ash/GGBS mortars}

Results from the investigation on consistency and setting time of mortars with different GGBS contents are shown in Figure 1. Mortar consistency seemed to be moderately affected by the GGBS substitution, although no clear trend could be observed. An increase of GGBS content seemed to lead to a reduction of the flow, but this reduction was not significant. Similar findings have also been reported in the literature $[3,15]$.

The initial setting times were however significantly affected with increasing content of GGBS. The initial setting time decreased from above 3 hours for $95 / 5$ mix to as low as 10 minutes in the case of 30/70 mix. The reduction in the initial setting time was found to be bilinear, with a more pronounced variation in the range $5 \%$ to $20 \%$ GGBS content (i.e. $95 / 5$ to $80 / 20$ mixes), in which the setting times were reduced from 3 hours to 1 and a half hour. The effect of GGBS inclusion on setting time had a lower slope in the GGBS range $20 \%$ to $70 \%$, in which the initial setting time varied from one and a half hours to about 10 minutes.

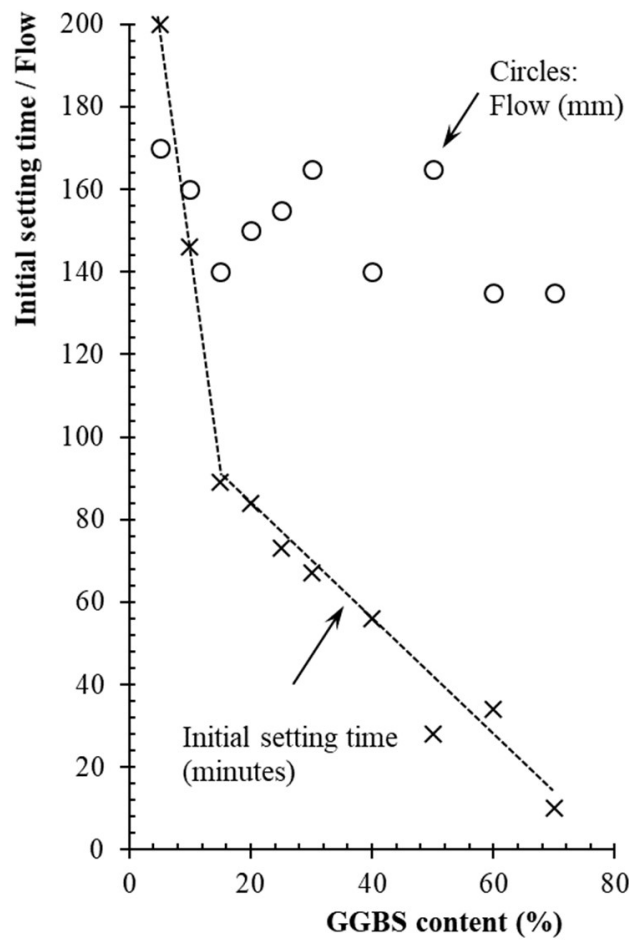

Figure 1. Consistency and setting time of fly ash/GGBS mortar mixes. Legend: $\times$ : initial setting time (minutes). ०: flow (mm). 


\subsubsection{Cube compressive strength}

Compressive strength of ambient temperature cured mortar cubes was found to increase with increasing GGBS content, see Figure 2. 28-day compressive strength varied from about 20 to $30 \mathrm{MPa}$ for GGBS contents up to $20 \%$ to about $75 \mathrm{MPa}$ for GGBS substitution of $70 \%$. The increase in the strength with increasing GGBS has also been reported by others $[3,15,16]$ and it is attributed to the densification of the matrix due to the formation of calcium silicate hydrate binding gel [15]. The increase in the compressive strength observed with increasing GGBS in the mix blend was also attributed to the coexistence of the geopolymeric gel (N-A-S-H) along with C-A-S-H type gel, which can lead to a denser and more homogeneous matrix and eventually to better mechanical properties [17].

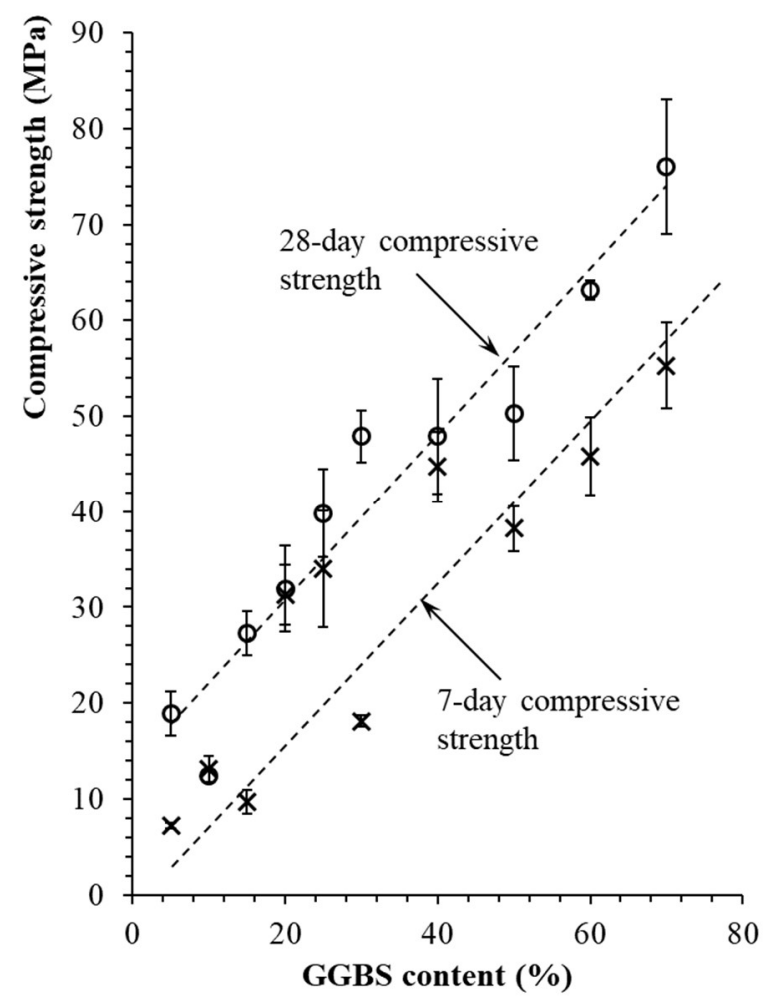

Figure 2. Compressive strength for fly ash/GGBS mortar blends.

Increasing GGBS allowed high compressive strengths to be obtained for samples cured at room temperature at a specific combination of activator dosages, i.e. $\mathrm{M}+7.5 \%$ and $\mathrm{AM}=1.25$. However, neat fly ash mortars have been shown to be capable of achieving compressive strengths as high as $60 \mathrm{MPa}$, when other activator dosages are used [14]. It is therefore of interest to understand how the activator dosages influence neat fly ash and fly ash/GGBS blended binders and to compare dosages leading to high compressive strengths.

\subsection{Activator dosages for high compressive strengths}

The mechanical strength of alkali activated binders is significantly influenced by the activator dosage, and a range of dosages resulting in high compressive strengths have been suggested $[2,14,18-20,65,66]$. 


\subsubsection{Effect of activator dosage on the compressive strength of $100 \%$ fly ash mortar cubes}

The effect of $\mathrm{M}+$, which is a proxy for the concentration of the alkali activator solution, and AM, which is a proxy for the amount of added silica in the activator solution, on compressive strength was first investigated for neat fly ash mortar cubes. $\mathrm{M}+$ was in the range 7.5 to $13.5 \%$, whilst AM was from 0.5 (corresponding to all sodium silicate) to $\infty$ (i.e. all sodium hydroxide). Figure 3 shows the combined effect of AM and M+ on the compressive strength of mortar cubes produced with $100 \%$ fly ash. Mix proportions of mortars are shown in Appendix A (Table A1 for production batches information, Table A2 for grams/litre conversion). The structure of sample labels is "precursor-M+-AM". In order to maintain the required w/s ratio, samples with $\mathrm{M}+$ equal to $12.5 \%$ and $13.5 \%$ were produced using sodium hydroxide solution at $40 \%$ concentration.

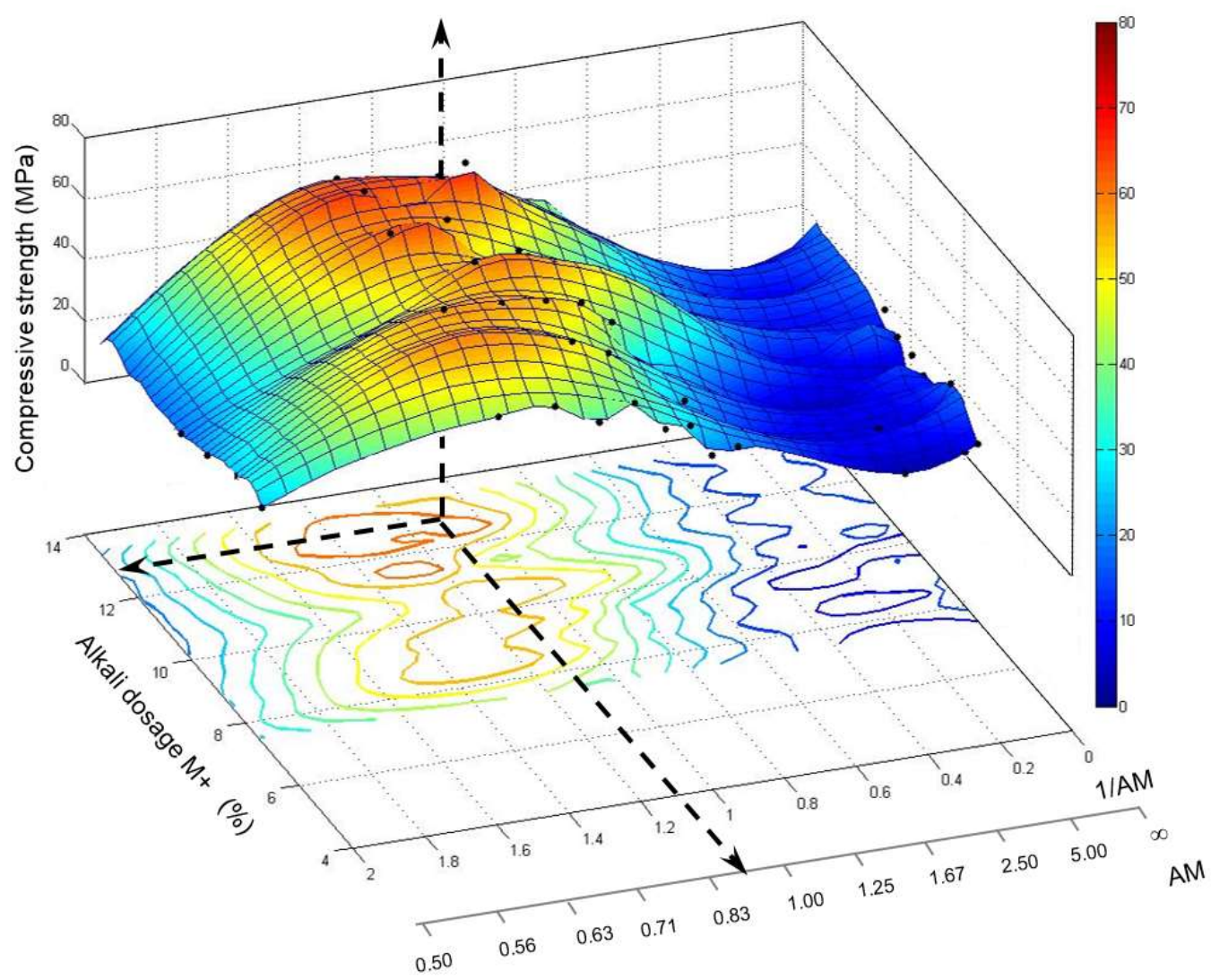

Figure 3. Combined effect of $\mathrm{M}+$ and $\mathrm{AM}$ on 28-day compressive strength for neat fly ash mortar mixes.

The "sweet spot" for compressive strength was found to be with an AM in the range 0.7 to 1.0 and an M+ in the range $11.5 \%$ to $13 \%$, where compressive strengths in excess of $60 \mathrm{MPa}$ were obtained.

The AM was found to have a strong effect on the compressive strength development, as compressive strengths higher than $50 \mathrm{MPa}$ were obtained with an AM in the range 0.7-1.0 regardless of the value of M+. Similar ranges have been reported in the literature [21-23]. This can be attributed to the enhancement of the degree of 
polymerisation of the dissolved species, leading to better mechanical properties. Hajimohammadi et al. [24] observed that high Si availability led to multiple aluminosilicate nucleation point opportunities, enhancing also the $\mathrm{Al}$ dissolution and the geopolymer gel formation. Compressive strength decreased as AM increased over 1.0, being in the range of about $10 \mathrm{MPa}$ when $\mathrm{AM}=\infty$ (i.e. when only $\mathrm{NaOH}$ solution was used as activator). This can be due to the non-availability of soluble silicates which affected the geopolymerisation process and, thus resulted in lower compressive strength. A decrease in compressive strength was also observed when the AM was low, i.e. 0.5 .

This strength reduction (around 50\%) can be attributed to the decrease in the $\mathrm{pH}$ of the system with the increase in sodium silicate solution. A drop in the $\mathrm{pH}$ from 14 to 12 when $\mathrm{AM}$ decreased from 1.25 to 0.5 has been observed in the literature [25]. The decrease in the $\mathrm{pH}$ affects the dissolution of the glassy aluminosilicate species from the precursor [26], which in turn affects the geopolymerization process and thus results in lower compressive strength. The amount of $\mathrm{SiO}_{2}$ in the activating solution (i.e. high soluble silicates) seemed to correlate well with the compressive strengths, confirming that the increase in $\mathrm{SiO}_{2}$ results in an increase in compressive strength until a $\mathrm{SiO}_{2} /$ binder mass ratio of about $15 \%$. Higher amounts of $\mathrm{SiO}_{2}$ did not increase the strength further. Data points corresponding to AMs at the two ends of the investigated range did not follow the trend, see Figure 4. As previously discussed, when the silicate contents were very low (i.e. AM > 30 in Figure 4) the geopolymerisation process was hindered, whilst excess of silicate (i.e. AM 0.5 in Figure 4) lowered the $\mathrm{pH}$ of the pore solution, reducing the dissolution of reactive species and thus negatively affecting the strength development.

The effect of $\mathrm{M}+$ on strength was also assessed. Within the optimum range of AM previously determined, compressive strength increased from 50 to $60 \mathrm{MPa}$ when $\mathrm{M}+$ of $8 \%$ increased to $12.5 \%$. The increases in compressive strength were more pronounced (i.e. from about 35 - $40 \mathrm{MPa}$ to about 55 to $60 \mathrm{MPa}$ ) when $\mathrm{M}+$ increased from $7.5 \%$ to $9.5 \%$. The strength increase was not significant for $\mathrm{M}+$ higher than $12.5 \%$. This was attributed to the saturation of the gel with alkali ions, i.e. less free water is available for speciation of silica and alumina oligomers from the dissolution of fly ash [14].

\subsubsection{Effect of activator dosage on the compressive strength of fly ash/GGBS mortar cubes}

The effect of activator dosage on compressive strength of blended binder was investigated on mixes with a GGBS content as high as 70\% (i.e. 30/70). Higher than 70\% GGBS substitution was not investigated as it resulted in quick setting times which did not allow proper casting of samples, for the $\mathrm{M}+$ and $\mathrm{AM}$ used in this series of mixes. Preliminary trials with 30/70 mixes showed satisfactory workability and reasonable working time. Neat GGBSbased binder typically requires lower $\mathrm{M}+$ dosages than neat fly ash $[6,23,27,28]$ and therefore the $\mathrm{M}+$ range 
selected was from 4.5 to $10.5 \%$, and the AM was in the range 0.75 to $\infty$ (i.e. $\mathrm{NaOH}$ solution only). Water-to-solid ratio (w/s) of 0.4 was adopted to ensure proper consistency of mixes. This value was slightly higher than the 0.37 used for neat fly ash mixes. Results are shown in Figure 5. Mix proportions of mortars are shown in Appendix A (Table A3 for production batches and Table A4 as grams/litre).

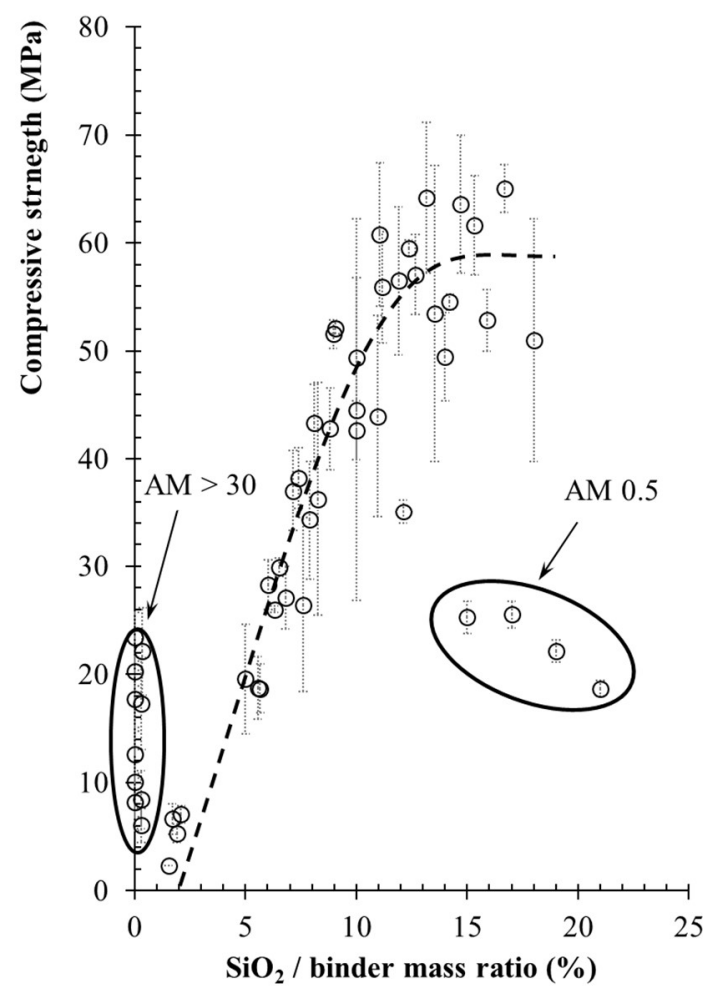

Figure 4. Relationship between mass ratio of $\mathrm{SiO}_{2}$ in the activating solution to the binder and 28-day compressive strength for neat fly ash mortar mixes. 


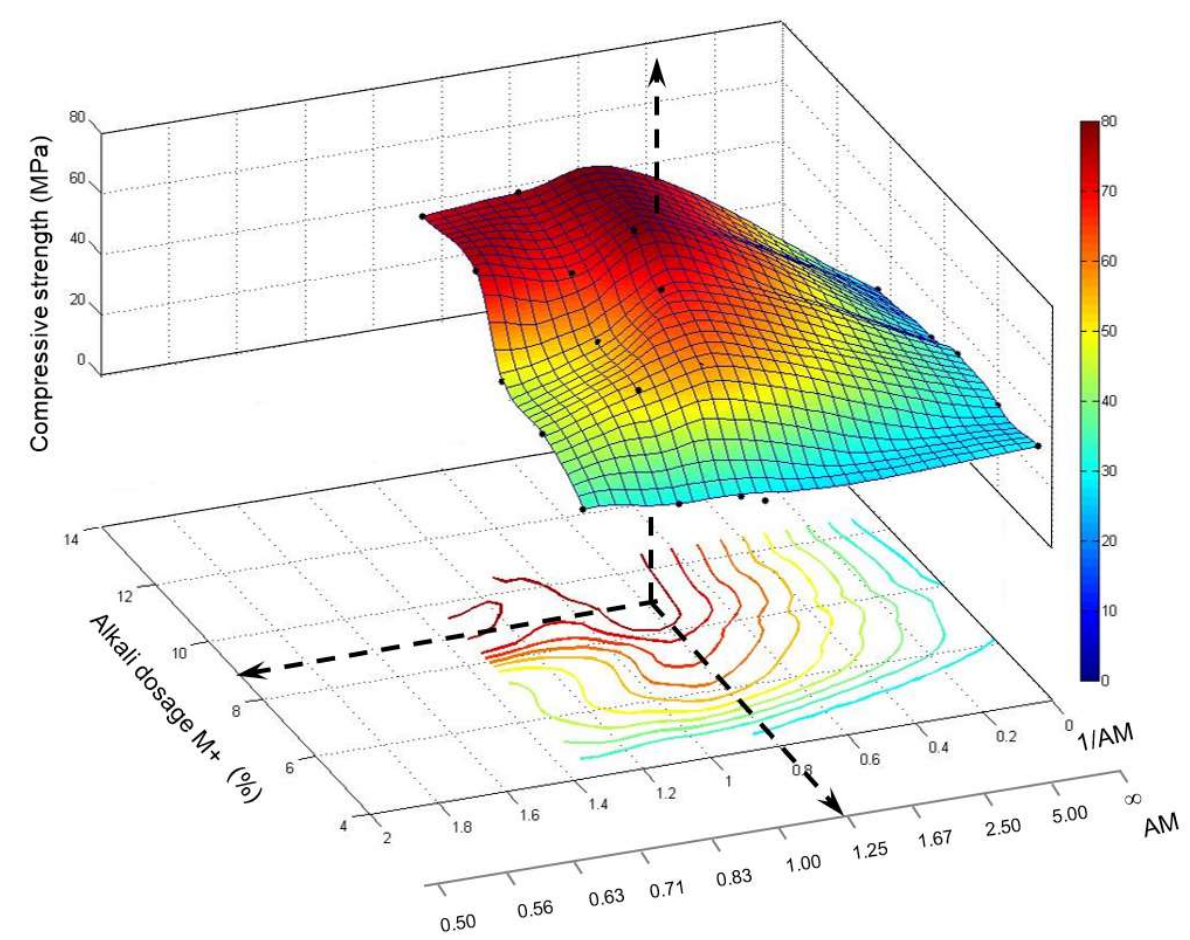

Figure 5. Effect of alkali dosage $\mathrm{M}+$ and alkali modulus AM on 28-day compressive strength of 30/70 blend

GGBS substitution had a significant effect on activator dosages required for achieving highest possible strength. 28-day strength higher than $60 \mathrm{MPa}$ was obtained with $\mathrm{AM}$ in the range 0.7 to 1.7 and $\mathrm{M}+$ in the range 6 to $10.5 \%$. $\mathrm{AM}$ values in the range 1.0 to 1.25 achieved mortar compressive strengths higher than $60 \mathrm{MPa}$ with $\mathrm{M}+$ as low as $6 \%$. Neat fly ash mixes, as reported previously, required an $\mathrm{AM}$ in the range 0.7 to 1 and $\mathrm{M}+$ in the range $11.5 \%$ to $12.5 \%$. The inclusion of GGBS in the mix allowed an increase of the AM and a decrease of the M+ for obtaining comparable strengths. This is a reduction of the amount of chemical activators required and therefore a reduction also of the cost and environmental footprint of these mixes.

When only $\mathrm{NaOH}$ was used in the mix (i.e. AM infinite), a strength equal to $30 \mathrm{MPa}$ was obtained regardless of the $\mathrm{M}+$ value. This can be attributed to the fact that the reaction in this case is mainly the hydration of calcium species of GGBS. This kind of reaction requires a pore solution with a $\mathrm{pH}$ high enough for breaking down the slag grain layer, allowing the water to reach the slag and the hydration to take place [29]. An M+ of $4.5 \%$ has been reported to be sufficient for neat GGBS systems, although inadequate for neat fly ash systems [30]. M+ of 4.5\% gave the same 28-day compressive strength of around $30 \mathrm{MPa}$ for all the investigated AM i.e. $0.75,0.95$, 1.15 and 1.25. This confirms that the reaction at this AM dosage is mainly due to the GGBS. The aluminosilicates from the fly ash do not contribute as this AM dosage is not sufficient for triggering the dissolution of fly ash particles. 
For higher alkali dosages $(\mathrm{M}+)$ of $6 \%, 7.5 \%, 8.5 \%$ and $10.5 \%$, the 'optimum' AM was found to be 1.25 (1/AM of 0.8 ). Mixes with $\mathrm{M}+$ of $8.5 \%$ and $10.5 \%$ gave compressive strengths of around $74 \mathrm{MPa}$, similar to those with $\mathrm{M}+$ of $7.5 \%$.

Higher chemical dosages have adverse effects on the mix, i.e. they cause reduction in the setting time, an increase of the $\mathrm{CO}_{2}$ footprint and an increase of the cost of AAC. Activator dosages of $\mathrm{M}+=7.5 \%$ and $\mathrm{AM}=1.25$ were therefore selected for investigation with fly ash/GGBS blends.

\subsection{Heat output of the reaction}

Heat output rate was determined with an isothermal calorimeter technique in order to understand the effects of GGBS inclusion and curing temperature on the reaction. Ex-situ tests (i.e. samples prepared outside the calorimeter) simulating curing temperatures $20^{\circ} \mathrm{C}$ and $70^{\circ} \mathrm{C}$ respectively were carried out on paste samples with different GGBS percentage substitution (100/0, 95/5, 82/20, 60/40, 30/70 and 0/100). Furthermore, in-situ tests (i.e. samples mixed directly in the calorimeter after temperature stabilisation) simulating room temperature conditions (i.e., $20^{\circ} \mathrm{C}$ ) were carried out on 4 paste samples, namely 30/70, 60/40, 80/20 and 100/0 in order to investigate the very early reaction which could not be investigated with the ex-situ method.

\subsubsection{Ex-situ isothermal calorimeter tests at $20^{\circ} \mathrm{C}$}

The solid powder was mixed with the liquid activator outside the isothermal calorimeter, and then the sample was placed in the testing chamber. Some time was then allowed for temperature stabilisation and only after this recording of the heat output started. The first 40 to 45 minutes of reaction could not be investigated.

Tests carried out at $20^{\circ} \mathrm{C}$ aimed at assessing the heat of reaction simulating room temperature curing. Mixes with significant content of GGBS (mixes 60/40 and above) showed one prominent peak, attributed to the dissolution and precipitation reaction leading to the formation of C-A-S-H type binding gel [3], see Figure 6(a). The peak appeared earlier and was higher as GGBS content increased. The peak occurred at around 10, 6, and 4 hours for 60/40, 30/70 and 0/100 samples respectively, whilst it was not observed in samples with GGBS content lower than $40 \%$. Similar peak but at longer reaction time i.e. 24 hours has been reported in the literature [31] for 50/50 fly ash/GGBS blend. The occurrence, magnitude and location of the peaks depend on various parameters such as the type and concentration of the activator, reaction temperature [32] and the nature and the reactivity of the raw materials.

The cumulative heat output increased with the increase in GGBS content, see Figure 6(b), which is consistent with what has been reported by others [31]. Values recorded up to 120 hours were in the range of 140, 130, and 
$90 \mathrm{~J} / \mathrm{g}$ for mixes 0/100, 30/70, and 60/40 respectively. Mixes with low GGBS content such as 80/20, 95/5 and $100 / 0$ showed low to very low cumulative heat outputs, with values of about 55,20 , and $10 \mathrm{~J} / \mathrm{g}$ respectively.

\subsubsection{Ex-situ isothermal calorimeter tests at $70^{\circ} \mathrm{C}$}

Tests carried out at $70{ }^{\circ} \mathrm{C}$ investigated the reaction simulating oven curing conditions. The reaction developed faster compared to tests carried out at $20^{\circ} \mathrm{C}$. After about three hours, residual heat flows of $2 \mathrm{~mW} / \mathrm{g}$ were recorded, see Figure 6(c). Peaks shifted toward shorter times as GGBS content increased as was observed for samples tested at $20{ }^{\circ} \mathrm{C}$. Peaks however occurred earlier, i.e., about 30 minutes, and with much higher intensities than those recorded for samples tested at $20^{\circ} \mathrm{C}$.

Cumulative heat generally increased with the increase in GGBS content, as the reaction of GGBS is exothermic involving mainly a hydration process. Cumulative heat outputs recorded for mixes $0 / 100,30 / 70$, and $60 / 40$ for up to 50 hours were comparable to the values recorded at $20^{\circ} \mathrm{C}$, see Figure $6(\mathrm{~d})$, suggesting that temperature accelerates the speed of the reaction but does not increase the amount of the reaction products.

Fly ash-rich mixes (i.e. $80 / 20,95 / 5$, and $100 / 0$ mixes) tested at $70{ }^{\circ} \mathrm{C}$ had heat outputs of 105,75 , and $60 \mathrm{~J} / \mathrm{g}$ respectively which are higher than those measured at $20^{\circ} \mathrm{C}$. These results confirmed that (a) fly ash reaction is less exothermic than GGBS reaction as it does not involve hydration, and (b) fly ash-rich mixes require energy (in the form of curing heat) for the reaction to develop. This was expected because of the low compressive strength development obtained when fly ash-rich mixes were cured at $20^{\circ} \mathrm{C}$. 

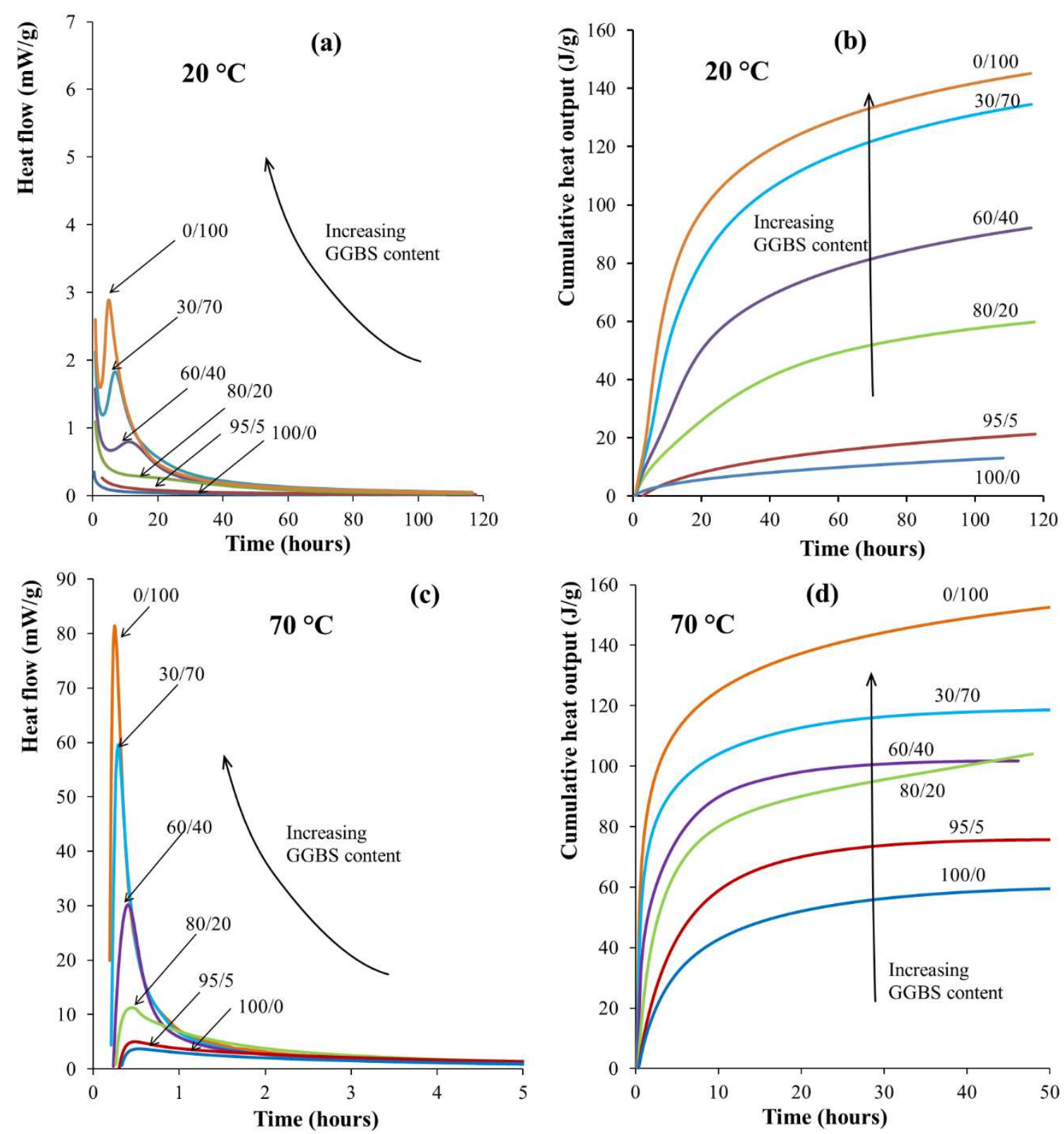

Figure 6. Ex-situ IC test results. (a) Heat flow at $20^{\circ} \mathrm{C}$. (b) Cumulative heat output at $20^{\circ} \mathrm{C}$. (c) Heat flow at $70^{\circ} \mathrm{C}$. (d) Cumulative heat output at $70^{\circ} \mathrm{C}$.

\subsubsection{In-situ isothermal calorimeter tests at $20^{\circ} \mathrm{C}$}

In-situ isothermal calorimeter tests were carried out at $20^{\circ} \mathrm{C}$ on four blends, i.e. $100 / 0,80 / 20,60 / 40$, and 30/70 fly ash/GGBS mixes. The constituent materials were placed in the testing chamber of the calorimeter which was then left to stabilise in terms of temperature before mixing the solid part with the liquid activator.

Two peaks were recorded in the first hour of testing. The first peak was recorded for all the samples (including neat fly ash sample) within about five minutes from the start of the mixing. This can be attributed to the wetting and dissolution of $\mathrm{Si}, \mathrm{Al}$ and $\mathrm{Ca}$ species from fly ash and GGBS $[33,34]$, see Figure 7(a). The highest initial peaks 
were recorded for fly ash-rich samples, whilst the lowest was recorded for GGBS-rich sample, i.e. 30/70. A second peak with a lower magnitude occurred after around 30 minutes of reaction, over a period of about 2 hours, in all the samples except neat fly ash, see Figure 6(a). This peak increased with the increase in GGBS content in the blend, and it can be attributed to the formation of C-A-S-H product from the reaction between $\mathrm{Ca}^{2+}$ dissolving from GGBS particles and silica anions from the activators $[32,35]$. This reaction was reported to play an important role in setting and mechanical properties in slag cement pastes [36].

A third peak was detected in samples with high content of GGBS i.e. 60/40 and 30/70 after about 10 to 15 hours, see Figure 7(a). These peaks can be attributed to the subsequent precipitation and formation of C-A-S-H reaction products, as these were not observed for fly ash-rich samples. These peaks were also found with the ex-situ technique.

The cumulative heat of the reaction increased with increasing GGBS content, confirming the exothermal nature of the GGBS hydration reaction, see Figure 7(b). Cumulative heat values after 100 hours were found to be similar to those obtained with ex-situ technique.
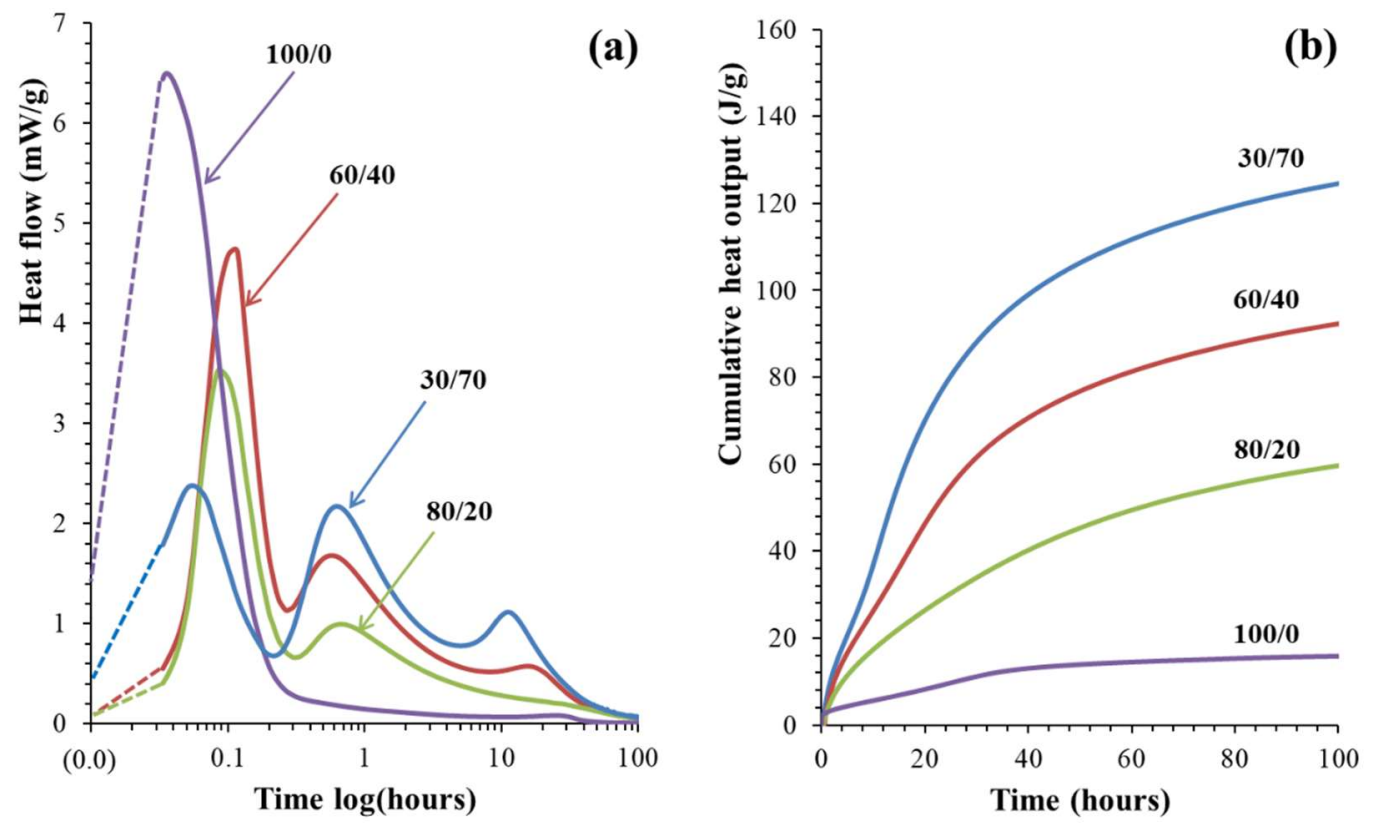

Figure 7. In situ IC curves for different fly ash/GGBS pastes: (a) heat flow in $\mathrm{mW} / \mathrm{g}$. log scale for time was used for magnifying the occurrence of early peaks. (b) Cumulative heat output in J/g of paste.

Results from isothermal calorimeter analysis seemed to suggest the presence of two different reaction mechanisms, according to the amount of GGBS in the mix:

a) With no or low GGBS content, the main exothermic reaction is due to the dissolution of $\mathrm{Si}$ and $\mathrm{Al}$ species from the binder. This reaction takes place very early (only observed with in-situ technique), but the 
hardening of geopolymeric matrix is slow at ambient temperature and needs external energy input (in the form of curing heating) to develop. This is confirmed by the comparison between the total heat output generated at $20^{\circ} \mathrm{C}$ and $70{ }^{\circ} \mathrm{C}$ and it is consistent with the results from compressive strengths on mortar samples.

b) With higher GGBS contents, the main exothermic reaction is due to the formation of C-A-S-H gel with the hydration of calcium silicate species. The heat output values increased with increasing GGBS content, in terms of heat flow rate peak intensity and cumulative heat of reaction, indicating that higher amounts of Ca species available for hydration resulted in higher volume of C-A-S-H produced, which may lead to denser and stronger gel structure. Samples with higher GGBS content showed higher compressive strength.

Increasing the curing temperature for high GGBS content mixes did not result in an increase of the total heat output (hence of the C-A-S-H gel production) but only in a faster reaction. This seems to suggest that curing GGBS-rich samples in oven would not result in an increase in the final compressive strength, but would only accelerate the strength development.

\subsection{Microstructure of pastes}

An extensive investigation on microstructural properties of eight sample pastes was carried out in order to assess in a qualitative and quantitative way the reaction products and to determine the effect of GGBS substitution on the microstructural development of the paste. Neat fly ash mixes (100-FA-1.25, 100-FA-0.85 and 100-FA-0.85b which had higher $\mathrm{M}+$ ) were oven cured at $70{ }^{\circ} \mathrm{C}$ for 7 days then stored in air tight containers at $20^{\circ} \mathrm{C}$ until testing (after 28 days). Samples with blends of fly ash and GGBS (05-GGBS-1.25, 20-GGBS-1.25, 40-GGBS-1.25, 70GGBS-0.95 and 70-GGBS- $\infty$ ) were cured at $20^{\circ} \mathrm{C}$. Unreacted fly ash and GGBS samples were also analysed for defining a baseline for comparison. Details of the samples are shown in Table 6.

Fly ash samples 100-FA-1.25, 100-FA-0.85 and 100-FA-0.85b were used as the control, i.e., for determining the microstructure and the reaction products with no GGBS. The effects of higher silicate dosage (100-FA-0.85) and of higher activator dosages (100-FA-0.85b) were also investigated.

The changes in reaction products when the GGBS content was increased from $5 \%$ to $70 \%$ was investigated for samples 05 -GGBS-1.25, 20-GGBS-1.25, 40-GGBS-1.25, and 70-GGBS-0.95. The mix 70-GGBS- $\infty$ used sodium hydroxide as the only activator (i.e., without sodium silicate). 
Table 6. Details on pastes investigated with microstructural techniques.

\begin{tabular}{|c|c|c|c|c|c|}
\hline Label & $\begin{array}{c}\text { fly ash/GGBS } \\
\text { ratio }\end{array}$ & $\begin{array}{c}\text { Curing } \\
\text { Condition }\end{array}$ & $\mathbf{M}+$ & AM & Aim of the investigation \\
\hline 100-FA-1.25 & $100 / 0$ & $70{ }^{\circ} \mathrm{C}$ & 7.5 & 1.25 & $\begin{array}{l}\text { Neat fly ash - assessment of microstructure for typical } \\
\text { chemical activator dosage. }\end{array}$ \\
\hline 100-FA-0.85 & $100 / 0$ & $70{ }^{\circ} \mathrm{C}$ & 7.5 & 0.85 & Neat fly ash - effect of increased content of silicates \\
\hline 100-FA-0.85b & $100 / 0$ & $70{ }^{\circ} \mathrm{C}$ & 11.5 & 0.85 & Neat fly ash - effect of increased amount of activator. \\
\hline 05-GGBS-1.25 & $95 / 5$ & $20^{\circ} \mathrm{C}$ & 7.5 & 1.25 & $\begin{array}{l}\text { Fly ash/GGBS - effect of GGBS substitution on the } \\
\text { microstructure ( } 5 \% \text { GGBS). }\end{array}$ \\
\hline 20-GGBS-1.25 & $80 / 20$ & $20{ }^{\circ} \mathrm{C}$ & 7.5 & 1.25 & $\begin{array}{l}\text { Fly ash/GGBS - effect of GGBS substitution on the } \\
\text { microstructure ( } 20 \% \text { GGBS). }\end{array}$ \\
\hline 40-GGBS-1.25 & $60 / 40$ & $20^{\circ} \mathrm{C}$ & 7.5 & 1.25 & $\begin{array}{l}\text { Fly ash/GGBS - effect of GGBS substitution on the } \\
\text { microstructure ( } 40 \% \text { GGBS). }\end{array}$ \\
\hline 70-GGBS-0.95 & $30 / 70$ & $20^{\circ} \mathrm{C}$ & 7.5 & 0.95 & $\begin{array}{l}\text { Fly ash/GGBS - effect of GGBS substitution on the } \\
\text { microstructure ( } 70 \% \text { GGBS). }\end{array}$ \\
\hline 70-GGBS- $\infty$ & $30 / 70$ & $20{ }^{\circ} \mathrm{C}$ & 7.5 & $\begin{array}{c}\mathrm{NaOH} \\
\text { only }\end{array}$ & $\begin{array}{l}\text { Fly ash/GGBS - effect of GGBS substitution on the } \\
\text { microstructure ( } 70 \% \text { GGBS) without silicates addition. }\end{array}$ \\
\hline
\end{tabular}

XRD, FTIR, TGA and SEM-EDX were the techniques used in this investigation. XRD analysis was used to identify the formation of some C-A-S-H in samples with GGBS, but it was not effective in assessing differences between other phases due to the amorphous nature of the main reaction products. With FTIR technique, qualitative differences among samples were observed, whilst TGA was used to estimate in a quantitative way the amount of hydrated reaction products. SEM-EDX methods were used to determine the morphology of reaction products and their chemical composition, and to assess the nature of the reacted gel.

\subsubsection{X-ray diffraction}

The crystalline phases observed with XRD analysis on three neat fly ash samples (i.e. 100-FA-1.25, 100-FA-0.85 and 100-FA-0.85b) were the same phases identified in the unreacted (raw) fly ash, namely Mullite, Quartz and traces of Hematite, see Figure 8(a). Corundum was used as an internal standard to quantify the amorphous percentage of the fly ash. No crystalline reaction product was observed in the reacted samples. This is due to the amorphous nature of the aluminosilicate hydrate binding gel rich in sodium (N-A-S-H). Peaks for the crystalline phases were lower compared with those of the unreacted material. 

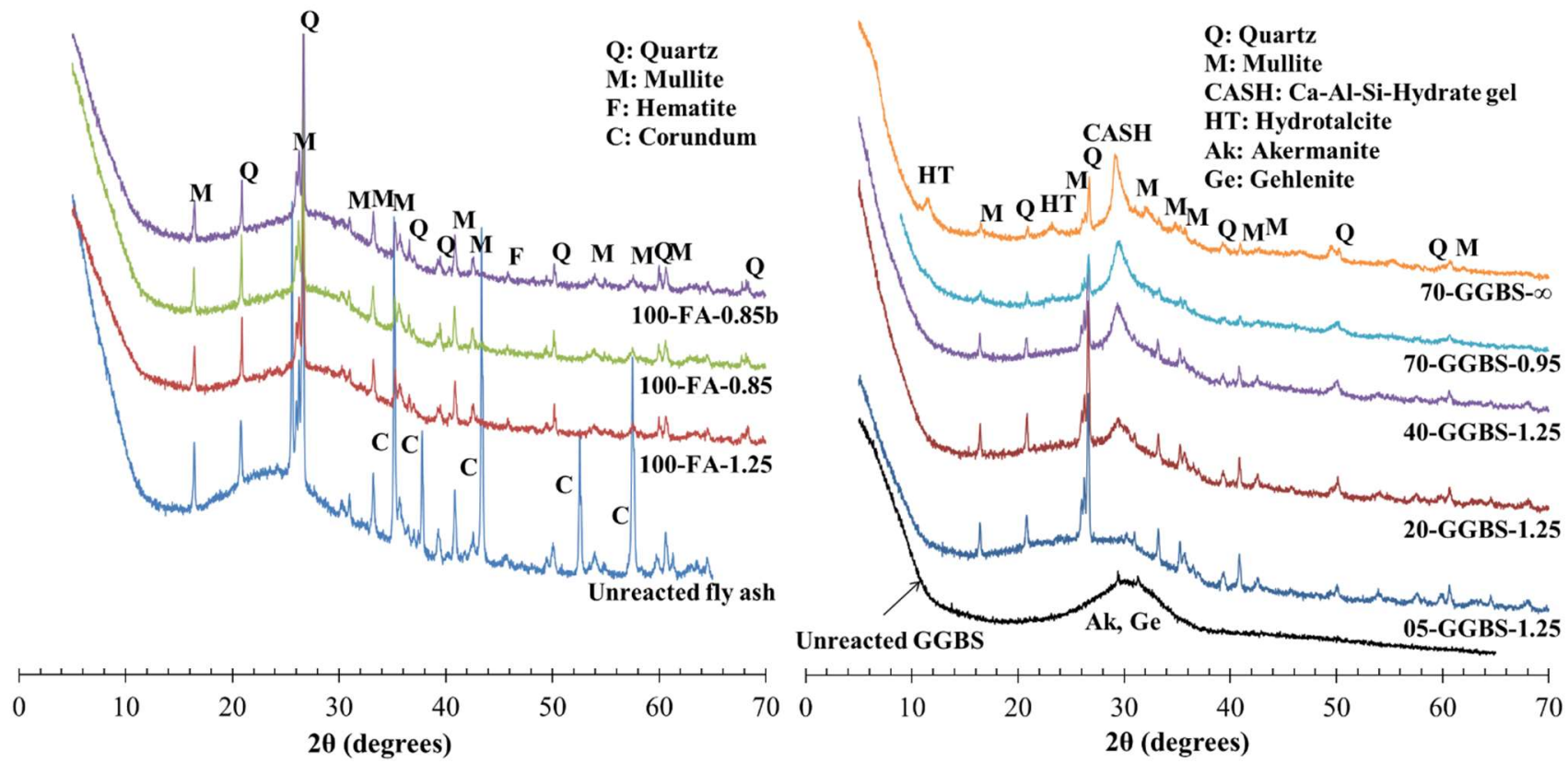

Figure 8. XRD spectra. (a) Neat fly ash pastes. (b) Pastes with GGBS.

The XRD pattern of unreacted GGBS showed traces of Akermanite and Gehlenite as the only crystalline phases, see Figure $8(\mathrm{~b})$. The crystalline phases observed in the raw fly ash, i.e., Quartz and Mullite, were also observed in fly ash/GGBS samples, although in a lower amount, due to the dilution resulting from blending. Sample 05GGBS-1.25, which contained only 5\% GGBS, showed a pattern similar to that of neat fly ash samples, with no presence of the C-A-S-H type gel hump. On the contrary, this latter was detected as the main reaction product in samples with GGBS $>20 \%(20-$ GGBS-1.25 to $70-$ GGBS- $\infty)$. The peak attributed to C-A-S-H seemed to increase with increasing GGBS content, which is in agreement with the increase in compressive strength of corresponding mortars: cube compressive strengths of about 20, 30, 45 and $70 \mathrm{MPa}$ were obtained for samples having GGBS contents of 5\%, 20\%, 40\% and 70\% respectively. The presence of C-A-S-H gel has previously been reported for alkali-activated slag [37] and slag and fly ash systems for slag contents $>25 \%[7,38]$.

Hydrotalcite was identified in the sample activated with $\mathrm{NaOH}$ solution only (i.e., 70-GGBS- $\infty$ ). Hydrotalcites are a class of anionic clays that are formed in highly caustic conditions ( $\mathrm{pH}$ greater than 9) as hydrated compounds of $\mathrm{Mg}, \mathrm{Al}$ and $\mathrm{CO}_{3}{ }^{2-}$. The absence of silica in the activating solution might have prevented the formation of geopolymeric gel (C-A-S-H), and consequently the Al was available for the crystallization of hydrotalcite. This is in agreement with the lower strength (30 MPa) obtained with the mortar with $70 \%$ GGBS and AM $\infty$ (i.e. no silicate in the activator solution). The compressive strength of mortar sample with $70 \%$ GGBS and AM 1.25 was above $70 \mathrm{MPa}$. Hydrotalcite has been identified in slag systems activated with different activators [37, 39, 40]. 
The amount of precipitation of hydrotalcite was found to increase with the increase of $\mathrm{MgO}$ content in the slag [41].

Due to the generally amorphous nature of precursors and reaction products, XRD analysis allowed qualitative assessments only. The utilisation of advanced approaches for the quantification of phases with partial or no known crystal structures (PONKCS) could give further quantitative insight into the nature of the reacted phases [62, 64].

\subsubsection{Fourier-transform infrared spectroscopy}

FTIR spectroscopy analysis was used to determine the presence and the position of peaks in the transmittance spectra obtained with raw materials and reacted pastes, see Figure 9.

In unreacted fly ash, the Si-O-(Si or Al) band was centred around $1057 \mathrm{~cm}^{-1}$, whereas a shift towards 1004,995 and $995 \mathrm{~cm}^{-1}$ was observed for 100-FA-1.25, 100-FA-0.85 and 100-FA-0.85b respectively. This shift can be attributed to the change of microstructure and the formation of the amorphous reaction products, with the partial replacement of $\mathrm{SiO}_{4}$ units by tetrahedral $\mathrm{AlO}_{4}$ units [42]. This confirmed the reaction development in the three samples, with 100-FA-1.25 showing a lesser extent of reaction compared with 100-FA-0.85 and 100-FA-0.85b. The peak observed at the wavenumber of $1650 \mathrm{~cm}^{-1}$ is attributed to the $-\mathrm{OH}$ bending vibration of chemically bound water, and it is present in all the three samples, confirming the presence of the reaction products. In the range $3200-3600 \mathrm{~cm}^{-1}$ a hump that is due to the stretching vibration modes of $\mathrm{H}-\mathrm{OH}$ groups has been identified for the reacted materials. This increased or broadened with the increase in the activator dosage (i.e. passing from 100-FA-1.25 to 100 -FA- 0.85 and $100-F A-0.85 b$ ), presumably due to the increase in the volume of reaction products. This may explain the improvement in compressive strengths of mortars produced with same activation dosages, i.e. 100-FA-1.25, 100-FA-0.85 and 100-FA-0.85b which had compressive strengths of 30, 45 and 75 MPa respectively. Quartz was observed in both the unreacted fly ash and the reacted pastes with bands at 795 and $775 \mathrm{~cm}^{-1}$ respectively $[7,43,44]$.

Figure 9(b), i.e. samples with GGBS, shows a main band centred at $985 \mathrm{~cm}^{-1}$ in the unreacted GGBS sample, which is assigned to the asymmetric stretching vibration of $\mathrm{T}-\mathrm{O}-\mathrm{T}$ bond ( $\mathrm{T}$ is tetrahedral $\mathrm{Si}$ or $\mathrm{Al})$. In the reacted blended fly ash/GGBS samples (05-GGBS-1.25 to 70-GGBS- $\infty$ ), the T-O-T band shifted toward a lower wavenumber as the content of slag increased. The bands were centred at 975, 965, 958, and $952 \mathrm{~cm}^{-1}$ for 05 GGBS-1.25, 20-GGBS-1.25, 40-GGBS-1.25 and 70-GGBS-0.95 respectively, see Figure 9(b). Shifting of the peaks toward a lower wavenumber in reacted pastes of GGBS rich blends can be due to the simultaneous activation of fly ash leading to the formation of a binding gel with more cross-linked aluminosilicate geopolymer gel (N-A- 
S-H) [7] and consequently increasing the compressive strength. However, the presence of GGBS in blended samples would shift the position of this peak for blended samples to a lower wavenumber irrespectively of the actual reaction, the main band of raw GGBS being at $985 \mathrm{~cm}^{-1}$. Further confirmation needs to be found from other microstructural analysis.

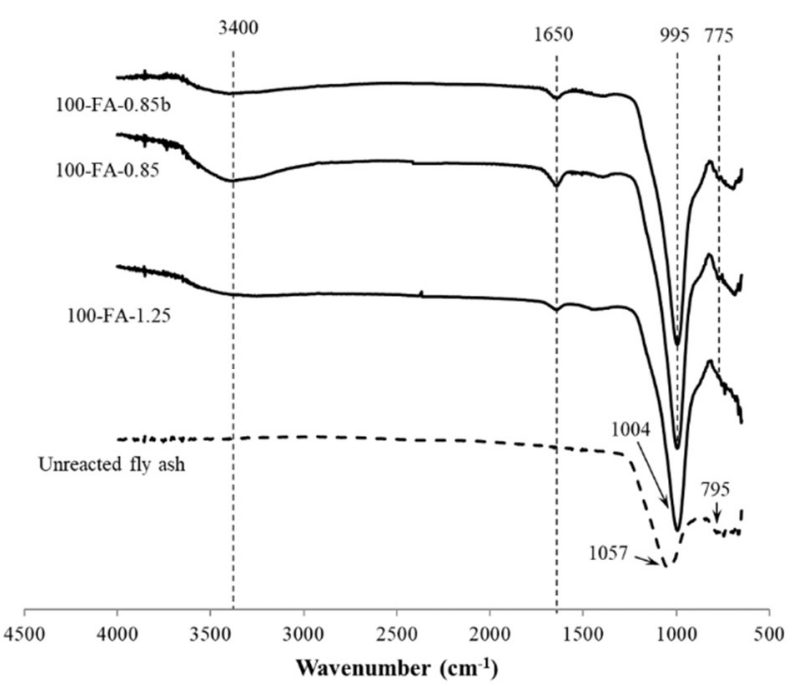

(a)

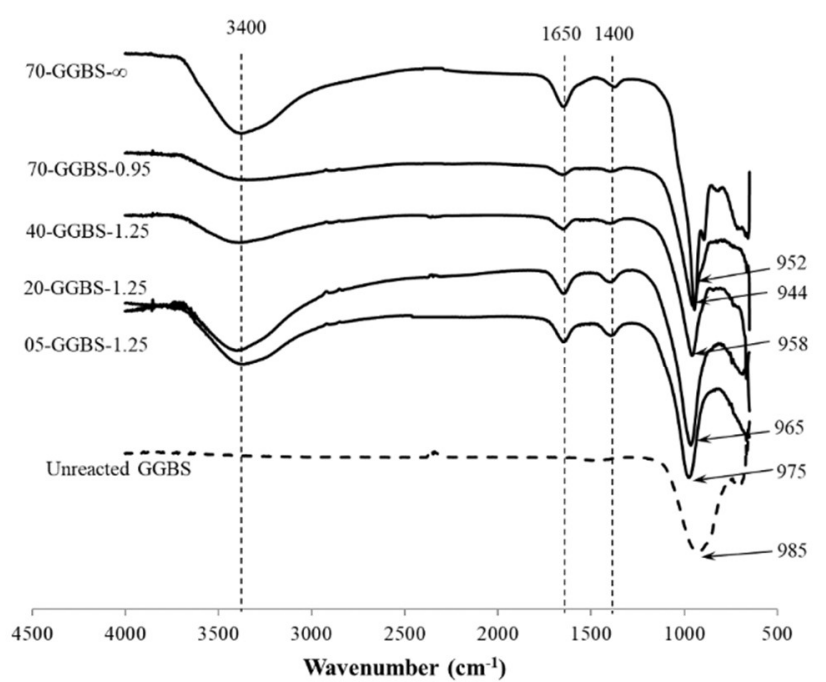

(b)

Figure 9. FTIR spectra. (a) Neat fly ash pastes. (b) Pastes containing GGBS.

In sample $70-G G B S-\infty(70 \%$ GGBS activated with $\mathrm{NaOH}$ only) the $\mathrm{T}-\mathrm{O}-\mathrm{T}$ band was centred at a lower wavenumber $\left(944 \mathrm{~cm}^{-1}\right)$ compared to the samples activated with both sodium hydroxide and sodium silicate activators. Activation dosage used for the production of this sample (only $\mathrm{NaOH}$ was added in the mix at a relatively low $\mathrm{M}+$ of $7.5 \%$ ) may have hindered the reactivity of fly ash, and therefore prevented the formation of either N-A-S-H or Al rich C-A-S-H binding gels. As a result, low Al C-A-S-H binding gel was formed along with hydrotalcite. SEM images of sample 70-GGBS- $\infty$ which is discussed later in this paper showed a larger extent of unreacted fly ash particles confirming the above.

A band centred at $1400 \mathrm{~cm}^{-1}$ was detected in all fly ash/GGBS samples and was attributed to $\mathrm{CO}_{3}{ }^{2-}$ probably due to some carbonation during the sample preparation.

As observed in neat fly ash reacted samples, the stretching-bending mode of $\mathrm{H}-\mathrm{OH}$ groups was centred at around $3400 \mathrm{~cm}^{-1}$ and appeared to increase or broaden with the increase of GGBS content, probably due to the development of the reaction products. Another band related to the reaction products was identified at around 1650 $\mathrm{cm}^{-1}$ due to the bending vibration of $\mathrm{O}-\mathrm{H}$ of the hydrated reaction products. 


\subsubsection{Thermo-gravimetric analysis}

TGA was performed on raw materials (as baseline for subsequent analysis) and on reacted pastes. Both unreacted fly ash and GGBS powders were found to be stable in terms of thermal decomposition, see Figure 10. A mass loss of about $4 \%$ was observed for fly ash in the range 600 to $1000{ }^{\circ} \mathrm{C}$, which was presumably due to the loss of ignition of carbon compounds (L.O.I. from XRF analysis was about 3.6\%). Gas emission analysis obtained with the mass spectrometer confirms this, since emissions recorded starting from $600{ }^{\circ} \mathrm{C}$ were attributed to $\mathrm{CO}_{2}$.

TGA analysis on neat fly ash pastes (samples 100-FA-1.25 to 100-FA-0.85b) showed moderate mass losses. In these materials, the reaction product is mainly a N-A-S-H (sodium - aluminium - silicate - hydrate) binding gel system. The mass loss at $300{ }^{\circ} \mathrm{C}$ (when water from the aluminosilicate type-gel is removed) was between 7 and $9 \%$, see Figure 10 . The amount of hydrated product in the paste is a proxy for the degree of reaction. Different amounts of hydrated compounds, according to the intensity of differential curve peaks centred at around $150^{\circ} \mathrm{C}$, were observed for 100-FA-1.25 on the one hand and 100-FA-0.85 and 100-FA-0.85b on the other. Such increased intensity has been attributed to a higher amount of aluminosilicate gel formation [45] and consequently leading to a higher compressive strength. Results suggest that 100-FA-1.25 reacted to a lesser extent compared to 100-FA0.85 and $100-F A-0.85 \mathrm{~b}$, and this is in agreement with the lower strengths obtained from mortar with AM 1.25. Mortars produced with same activator dosages as 100-FA-1.25, 100-FA-0.85 and 100-FA-0.85b gave compressive strength of 30, 45 and 75 MPa respectively. 100-FA-1.25 showed a mass loss at high temperature (associated with $\mathrm{CO}_{2}$ emission at $600-800^{\circ} \mathrm{C}$ ) similar to that of the unreacted fly ash, see Figure 10 . This behaviour can be related to the relatively poor reactivity of sample 100-FA-1.25, which resulted in a proportion of unreacted fly ash particles higher than in the other two samples, i.e., 100-FA-0.85 and 100-FA-0.85b, and consequently in a lower production of geopolymeric gel, which ultimately led to a lower compressive strength.

The analysis of the TG curves and the derivative TG (DTG) curves of samples containing GGBS (samples 05GGBS-1.25 to 70 -GGBS- $\infty$ ) indicated that the main mass losses occurred in the region $40-160{ }^{\circ} \mathrm{C}$, with peaks centred in the range $90-130^{\circ} \mathrm{C}$. This region corresponds to the dehydration of physically bound water in the gel structure (mainly in the pore network). The water gas emission curves are the mirror image of the DTG, confirming that the main mass loss happens due to the dehydration process. 


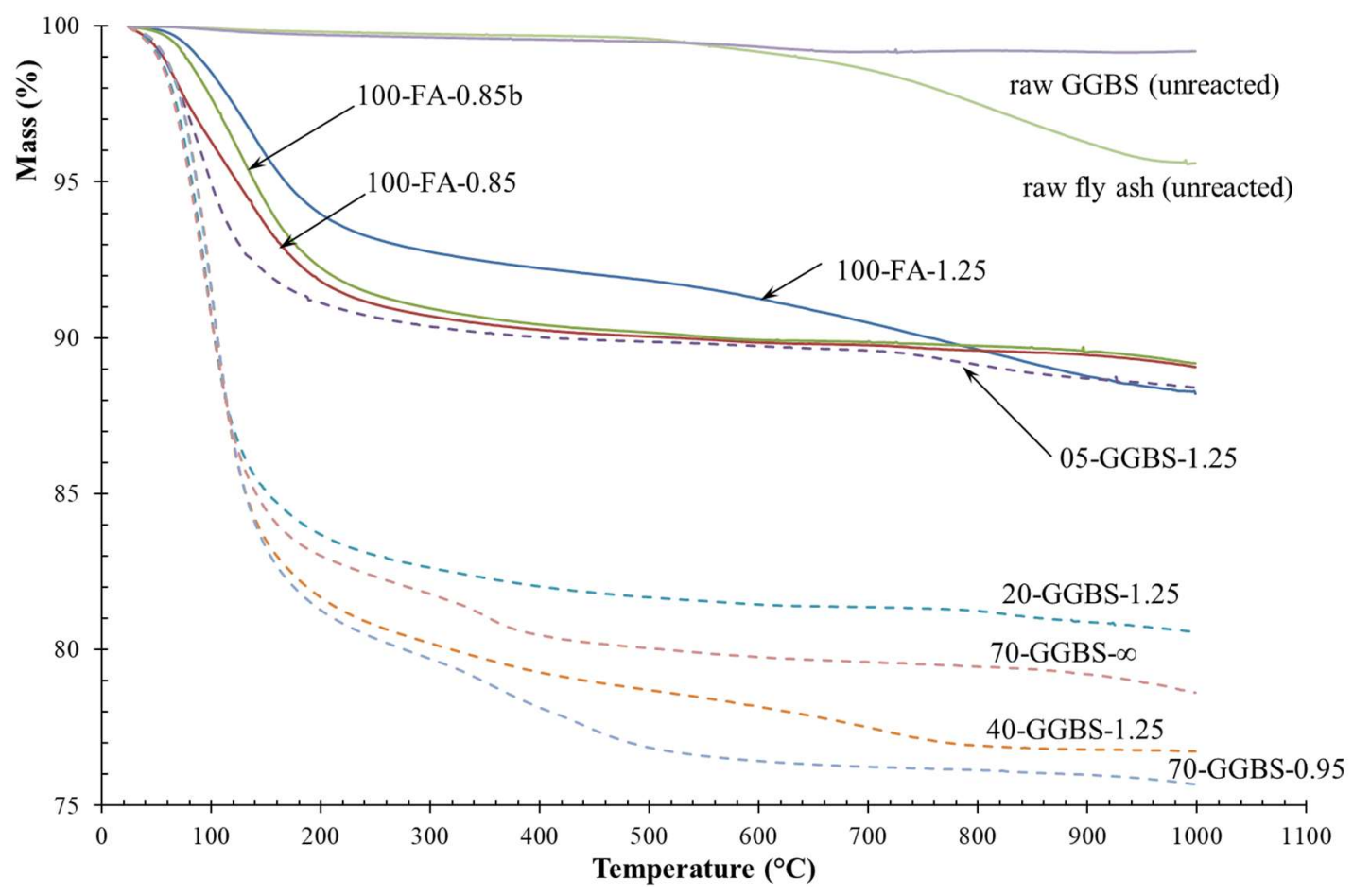

Figure 10. Thermo gravimetric curves of raw materials (fly ash and GGBS), neat fly ash pastes and pastes containing GGBS.

GGBS-rich pastes (high calcium pastes) show higher mass losses due to the dehydration process. In these materials, the hydration products are mainly related to the C-(N)-A-S-H (calcium - aluminium - silicate - hydrate) systems, with sodium ions in the structure. The dehydroxylation occurs from around $300{ }^{\circ} \mathrm{C}$ to $600{ }^{\circ} \mathrm{C}[46]$, and it is completed by $550-600{ }^{\circ} \mathrm{C}$. The total mass loss up to $600^{\circ} \mathrm{C}$ can be taken as a relative measure of the degree of reaction. Mass losses increasing from 10\% (05-GGBS-1.25) to around 24\% (70-GGBS-0.95) were observed with increasing GGBS content, which corresponded to an increase in the volume of reaction products. This explains the high compressive strength obtained in these formulations, see Figure 11. The analysis confirmed that increasing GGBS content in the mix resulted in a higher volume of C-(N)-A-S-H gel. 


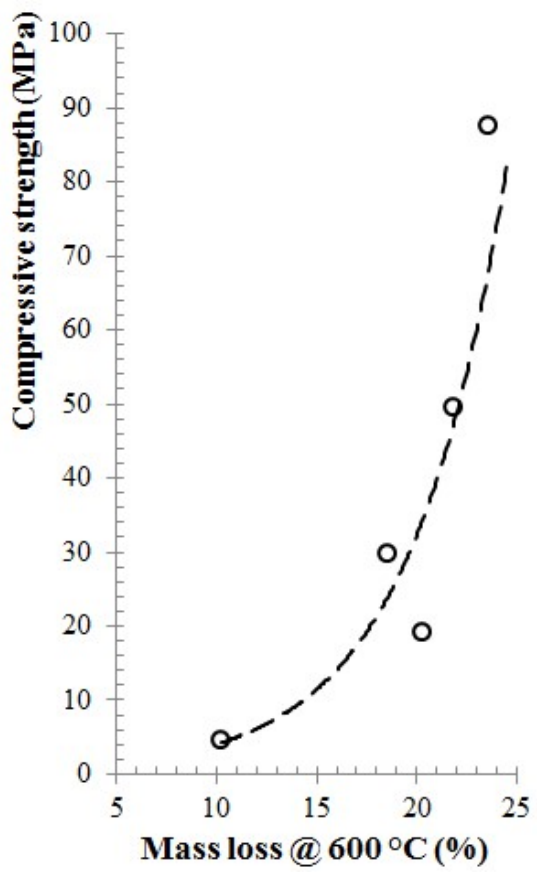

Figure 11. Relationship between compressive strength and hydrated products (observed as mass loss up to 600 ${ }^{\circ} \mathrm{C}$ ) for fly ash/GGBS pastes.

The comparison between samples 70-GGBS-0.95 and 70-GGBS- $\infty$ gave insights into the effects of silicates in the activating solutions on the reaction products. Sample 70-GGBS- $\infty$ was activated with $\mathrm{NaOH}$ only, and shows a reduced amount of hydration products when compared to 70 -GGBS-0.95 (18.2\% vs. $20.3 \%$ at $300{ }^{\circ} \mathrm{C}$ respectively). This indicates a lack of reactivity and therefore a deficiency in binding gel formation (in agreement with the difference in compressive strength mentioned above). Furthermore, an isolated peak at around $350{ }^{\circ} \mathrm{C}$ can be observed in sample 70-GGBS- $\infty$, see Figure 12. This peak is associated with the dehydration of hydrotalcite, which decomposes in the range of $270-400{ }^{\circ} \mathrm{C}[7,41]$. The presence of hydrotalcite as a reaction product when $\mathrm{NaOH}$ only was used as an activator was also confirmed from XRD analysis. On the other hand, 70-GGBS-0.95 differential thermogram shows a broader hump in the range $300-600{ }^{\circ} \mathrm{C}$, which is due to the dehydroxilation by condensation of the bound silanol (-Si-OH end group) groups, and is completed at around 600 ${ }^{\circ} \mathrm{C}[46,47]$, with no evidence of hydrotalcite. 


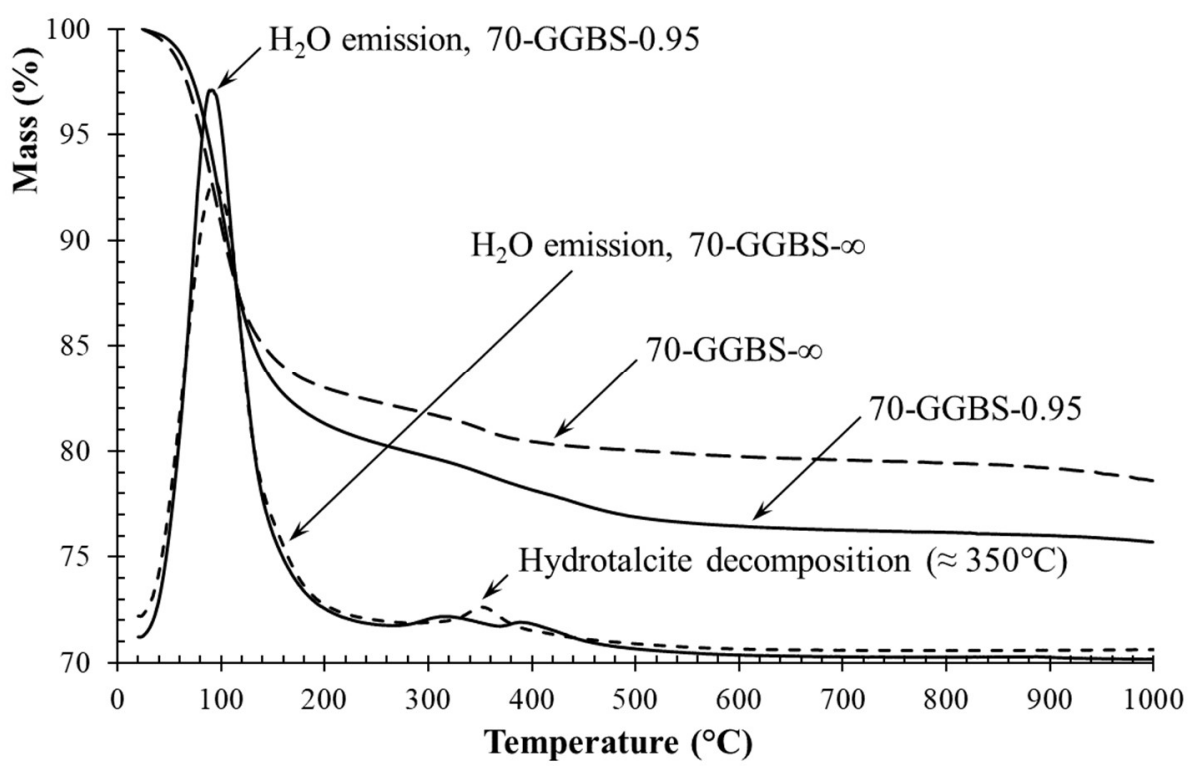

Figure 12. Thermogravimetry and $\mathrm{H}_{2} \mathrm{O}$ emission curves for 70-GGBS-0.95 and 70-GGBS- $\infty$ samples.

\subsubsection{Scanning electron microscopy (SEM) with energy dispersive X-ray analysis (EDX)}

SEM and EDX techniques were used to study the morphology and the chemical composition of the geopolymeric matrix such as: (a) unreacted or partially reacted particles (cenospheres for fly ash and flakes for GGBS); (b) matrix gels; (c) crystals from raw materials or from precipitation during the reaction. Due to the unavailability of polished samples, EDX analysis should be considered with a degree of uncertainty.

Neat fly ash pastes (samples 100-FA-1.25 to 100-FA-0.85b) activated with different dosages resulted in three different observed morphologies. The magnification 3000X (30 $\mu \mathrm{m})$ allowed to observe much larger amount of unreacted (or partially reacted) cenospheres in sample 100-FA-1.25 than those observed in samples 100-FA-0.85 and 100-FA-0.85b. Denser microstructures were found in samples 100-FA-0.85 and 100-FA-0.85b. This indicated better reactivity of fly ash and therefore better mechanical properties as confirmed by higher compressive strength. When low quantities of free $\mathrm{Si}$ ions were available, i.e., for low activation dosages, $\mathrm{Al}$ was present in the cenospheres only and did not fully participate in the formation of the gel structure, limiting also the presence of $\mathrm{Na}$ in the binding gel. With higher $\mathrm{Si}$ availability, i.e. higher activator dosages, the distribution of $\mathrm{Al}, \mathrm{Na}$ and $\mathrm{Si}$ was found to be more even in the matrix, and the dissolution of solid aluminosilicates was nearly complete [48]. Higher Si availability resulted in higher compressive strength and this has been associated with a more thorough dissolution of $\mathrm{Al}[24]$.

The SEM and EDX analysis confirmed therefore that 100-FA-1.25 did not fully react, whereas 100-FA-0.85 and 100-FA-0.85b showed higher levels of aluminosilicate gel structure formation. 
Samples with lower GGBS content i.e. 05-GGBS-1.25 and 20-GGBS-1.25 showed larger amounts of unreacted particles, and a less dense matrix was found in sample 05-GGBS-1.25. When GGBS content was increased to $20 \%$ (i.e., sample 20-GGBS-1.25), the matrix became denser with smaller amount of unreacted particles and fewer visible pores. The structure of the matrix increased in density and homogeneity with increasing GGBS, i.e., samples 40-GGBS-1.25 and 70-GGBS-0.95, with a better-developed microstructure showing more glassy texture, which in turns implied more binding gels. Thus the higher compressive strengths obtained with increasing GGBS. The effects of different activating dosages on a sample containing 70\% GGBS on the morphology were assessed by comparing 70-GGBS-0.95 (30/70 blend activated using sodium silicate and sodium hydroxide) with 70-GGBS$\infty$ (30/70 blend activated with sodium hydroxide only). Sample 70-GGBS- $\infty$ showed a larger amount of unreacted (or partially reacted) particles, both from fly ash and from GGBS precursors, with a coarse bonding with the gel. Sample 70-GGBS-0.95, on the other hand, showed a very dense and uniform matrix. The difference in compressive strength was significant (above $70 \mathrm{MPa}$ for sample 70-GGBS-0.95 and around $30 \mathrm{MPa}$ for sample 70-GGBS- $\infty$ ), confirming a lack of reaction due to the lack of silicates in the solution, which led to a reduced amount of binding gel forming.

\subsubsection{Chemical composition of reaction products (EDX)}

The chemical composition of the reaction products, assessed via EDX analysis, varied depending on the GGBS amount in the blend, see Table 7. In the sample with low GGBS content such as 05-GGBS-1.25, Si/Al atomic ratios ranged from 2.5 to 2.9 with an average ratio of 2.8 . $\mathrm{Ca} / \mathrm{Si}$ ratios were in the range of 0.1 to 0.3 with an average ratio of 0.2 . The $\mathrm{Si} / \mathrm{Al}$ ratio of sample $05-\mathrm{GGBS}-1.25$ was similar to that of neat fly ash samples (100FA-1.25 to $100-F A-0.85 b$ ) suggesting the dominance of fly ash-driven reactions in these samples due to the low GGBS content. The reaction products in sample $05-\mathrm{GGBS}-1.25$ consisted mainly of $\mathrm{Si}, \mathrm{Al}$ and $\mathrm{Na}$ whereas the content of Ca was relatively low in the matrix. As the content of GGBS increased in the sample, the amount of $\mathrm{Ca}$ increased and the amount of $\mathrm{Si}$ and $\mathrm{Al}$ appeared to decrease in the matrix. Furthermore, the amount of the main elements and their atomic ratios varied depending on the blend. $\mathrm{Ca} / \mathrm{Si}$ and $\mathrm{Si} / \mathrm{Al}$ ratios (in samples 05-GGBS-1.25 to 70-GGBS-0.95) increased with increasing GGBS. The highest $\mathrm{Ca} / \mathrm{Si}$ ratio was obtained in sample 40-GGBS$1.25(\mathrm{Ca} / \mathrm{Si}=0.7)$ which was similar to that of 70 -GGBS-0.95 (0.6) and the highest $\mathrm{Si} / \mathrm{Al}$ ratio was found in sample 70-GGBS-0.95 ( $\mathrm{Si} / \mathrm{Al}=3.1)$. This is because of the higher $\mathrm{Si}$ content in the activating solution and explains the high compressive strength obtained for mortar samples with the same composition (above $70 \mathrm{MPa}$ ). The higher strengths are due to the better geopolymerization or highly cross-linked structures of the binding gels [10], which lead to more compact and denser matrix and therefore better mechanical properties. 
Table 7. Average values (\%) and the standard deviation in the brackets of the main elements and their atomic ratios in the matrix, assessed via EDX analysis.

\begin{tabular}{lccccc}
\hline Sample label & Ca & Si & Al & Ca/Si & Si/Al \\
\hline 05 -GGBS-1.25 & $2.5(0.7)$ & $13.3(0.4)$ & $4.8(0.2)$ & $0.2(0.0)$ & $2.8(0.2)$ \\
20-GGBS-1.25 & $4.3(1.7)$ & $12.0(1.0)$ & $5.3(1.4)$ & $0.4(0.2)$ & $2.3(0.4)$ \\
$40-G G B S-1.25$ & $6.7(1.4)$ & $9.9(1.6)$ & $3.9(0.4)$ & $0.7(0.2)$ & $2.5(0.6)$ \\
$70-G G B S-0.95$ & $6.5(1.9)$ & $10.3(1.8)$ & $3.3(0.6)$ & $0.6(0.1)$ & $3.1(0.6)$ \\
$70-G G B S-\infty$ & $12.5(4.2)$ & $8.6(2.5)$ & $3.7(0.9)$ & $1.5(0.6)$ & $2.3(0.3)$ \\
\hline
\end{tabular}

The chemical composition of the reaction products of sample 70-GGBS- $\infty$ (i.e., activated with $\mathrm{NaOH}$ solution only) was different from that of the other blends, especially in the amount of Ca. The amount of Ca in the matrix was higher than that of the other samples including 70-GGBS-0.95, which had the same GGBS content. The Ca/Si ratio was 1.5 , i.e., the highest amongst all investigated blends. This ratio is higher than the typical ratios which are reported in the literature in the range of 1.0 to 1.2 for neat alkali-activated slag systems $[7,39,49]$. This high $\mathrm{Ca} / \mathrm{Si}$ ratio is more similar to that found in $\mathrm{C}-\mathrm{S}-\mathrm{H}$ gel in Portland cement systems, which varies from 1.2 to 2.3 [50]. The reaction in this sample seems to be the hydration of GGBS, leading to the formation of C-A-S-H gel that is high in Ca. There is very little contribution from the fly ash as unreacted fly ash particles were easily identified in SEM images. The compressive strengths were about $30 \mathrm{MPa}$ regardless of the dosage $(\mathrm{M}+)$, suggesting that the reaction involves mainly the hydration of GGBS, since there is absence of silicate into the activating solution,

The variation of the chemical composition of the binding gel due to the increasing GGBS content suggests the development of different reaction products. In sample 05-GGBS-1.25, the reaction product was mainly alkaline aluminosilicate hydrate geopolymer gel (N-A-S-H) with $\mathrm{Si} / \mathrm{Al}$ ratios of 2.5-2.9 and a low $\mathrm{Ca} / \mathrm{Si}$ ratio of $0.1-0.3$. The chemical composition for sample 20-GGBS-1.25 was different from that of 05-GGBS-1.25, as higher Ca/Si ratios 0.2 to 0.6 were obtained, indicating more $\mathrm{Ca}$ in the gel. This suggests the formation of $\mathrm{C}-\mathrm{A}-\mathrm{S}-\mathrm{H}$ type binding gel along with the geopolymer gel (N-A-S-H). The existence of C-A-S-H gel in samples with as low as $20 \%$ GGBS content was confirmed by TGA and XRD analyses discussed earlier. The dominance of the geopolymer gel (N-A-S-H) among reaction products with GGBS content less than $25 \%$ has also been reported by others [10, 51]. In samples with high GGBS content such as 40-GGBS-1.25 and 70-GGBS-0.95, the ratios of Ca/Si increased significantly compared to samples 05-GGBS-1.25 and 20-GGBS-1.25. The two samples had similar Ca/Si ratios 
in the range of $0.5-1.0$ with average values of 0.7 and 0.6 for 40-GGBS-1.25 and 70-GGBS-0.95 respectively. These ratios are consistent with the chemical composition of C-A-S-H gel in slag systems and therefore the dominant reaction product in the gel was C-A-S-H, possibly coexisting with geopolymer type binding gel N-AS-H. These findings are in agreement with previous studies [3, 30, 51, 52]. The evolution of the reaction resulted in higher compressive strength and reduced setting time with increasing GGBS content, which can also be attributed to the co-existence of the above mentioned binding gels [3]. However, using morphological images and EDX chemical analysis of the gels, it was not possible to clearly distinguish the two reaction products as they appear to be intermixed at a too small scale to be spotted by EDX analysis [7, 51, 53]. This may suggest the formation of a hybrid binding gel (C-N-A-S-H) that improved the mechanical properties of the matrix $[7,51,54]$. Pseudo-ternary diagrams of the ratios of $\mathrm{Al}, \mathrm{Ca}$ and $\mathrm{Na}$ normalised by the quantity of Si for neat fly ash samples and fly ash /GGBS blends are shown in Figures 13 and 14 respectively. The unreacted/partially reacted fly ash particles appeared to have similar composition to that of the precursor material but with lower quantity of calcium. This suggests that the calcium was dissolved by the activators. The difference between theoretical and EDX measured gel composition was found to be higher for sample 100-FA-1.25 than for the other neat fly ash samples (100-FA-0.85 and 100-FA-0.85b). The quantity of Al in the binding gel of sample 100-FA-1.25 also appeared to be lower. This can be due to the poor dissolution of $\mathrm{Al}$ from the precursor, especially in samples with higher AM (i.e., low soluble silicate), which reduced the availability of $\mathrm{Al}$ in the gel nucleation [24]. As the activator dosage increased (samples 100-FA-0.85 and 100-FA-0.85b), the gel compositions obtained by EDX were closer to the calculated values (see Figure 13). This indicates better reactivity and homogeneity of the binding gel. The quantity of $\mathrm{Al}$ in the gel increased in samples $100-\mathrm{FA}-0.85$ and $100-\mathrm{FA}-0.85 \mathrm{~b}$ with lower alkali modulus (AM 0.85) compared to sample 100-FA-1.25 (AM 1.25). An increase in alkali dosage (M+) from 7.5\% (100-FA-1.25) to $11.5 \%$ (100-FA-0.85b) increased the sodium content of the binding gel as can be seen from Figure 13. Low calcium N-A-S-H binding gel was identified as the main reaction product in these formulations. 


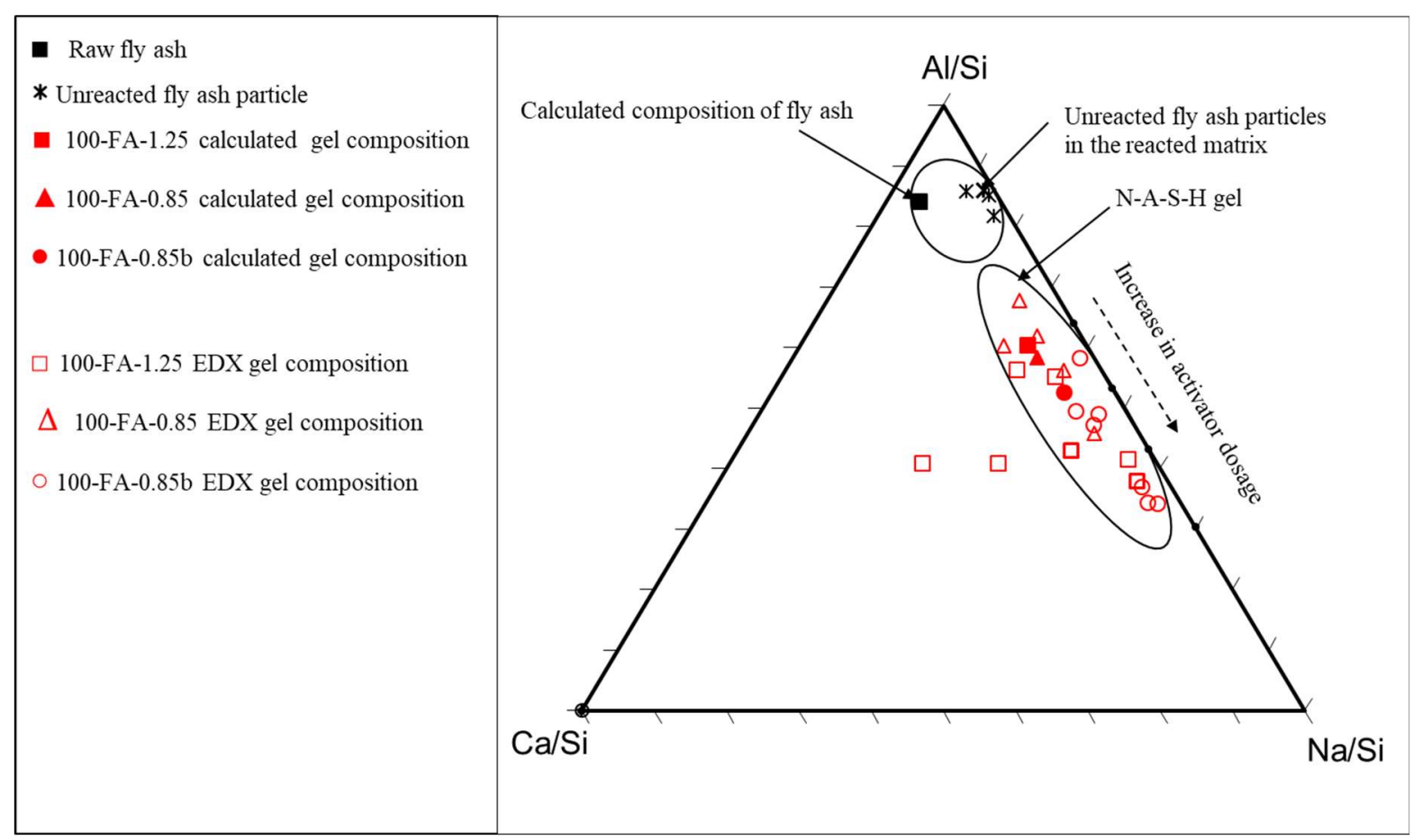

Figure 13. Pseudo-ternary diagram showing $\mathrm{Al} / \mathrm{Si}, \mathrm{Na} / \mathrm{Si}$ and $\mathrm{Ca} / \mathrm{Si}$ molar ratios for neat fly ash samples.

In the case of fly ash/GGBS blends (see Figure 14), the unreacted GGBS particles analysed with EDX showed similar chemical composition to those of the raw GGBS. However, the chemistry of partially reacted GGBS particles was similar to the composition of the binding gel, indicating that those particles had reacted to some degree that enabled the formation of the gel (C-A-S-H). Sample 05-GGBS-1.25 had a gel chemical composition similar to that of neat fly ash samples. The increase of GGBS content in the system led to the formation of binding gels with different calcium content, see Figure 14.

Two main categories of the gel can be detected: (a) a low calcium gel with similar chemical composition as that of neat fly ash systems, and (b) a binding gel with higher calcium content. It was also observed that both low calcium and high calcium gels were present in the same samples (20-GGBS-1.25 and 70-GGBS-0.95), which may confirm the coexistence of both N-A-S-H and C-A-S-H from the activation of fly ash and GGBS respectively. Sodium silicate crystals were also detected mainly in sample $05-$ GGBS-1.25. This can be due to the poor reactivity of this sample at room temperature due to its high fly ash content (95\%), which led to some amount of activator chemicals to crystalize. 


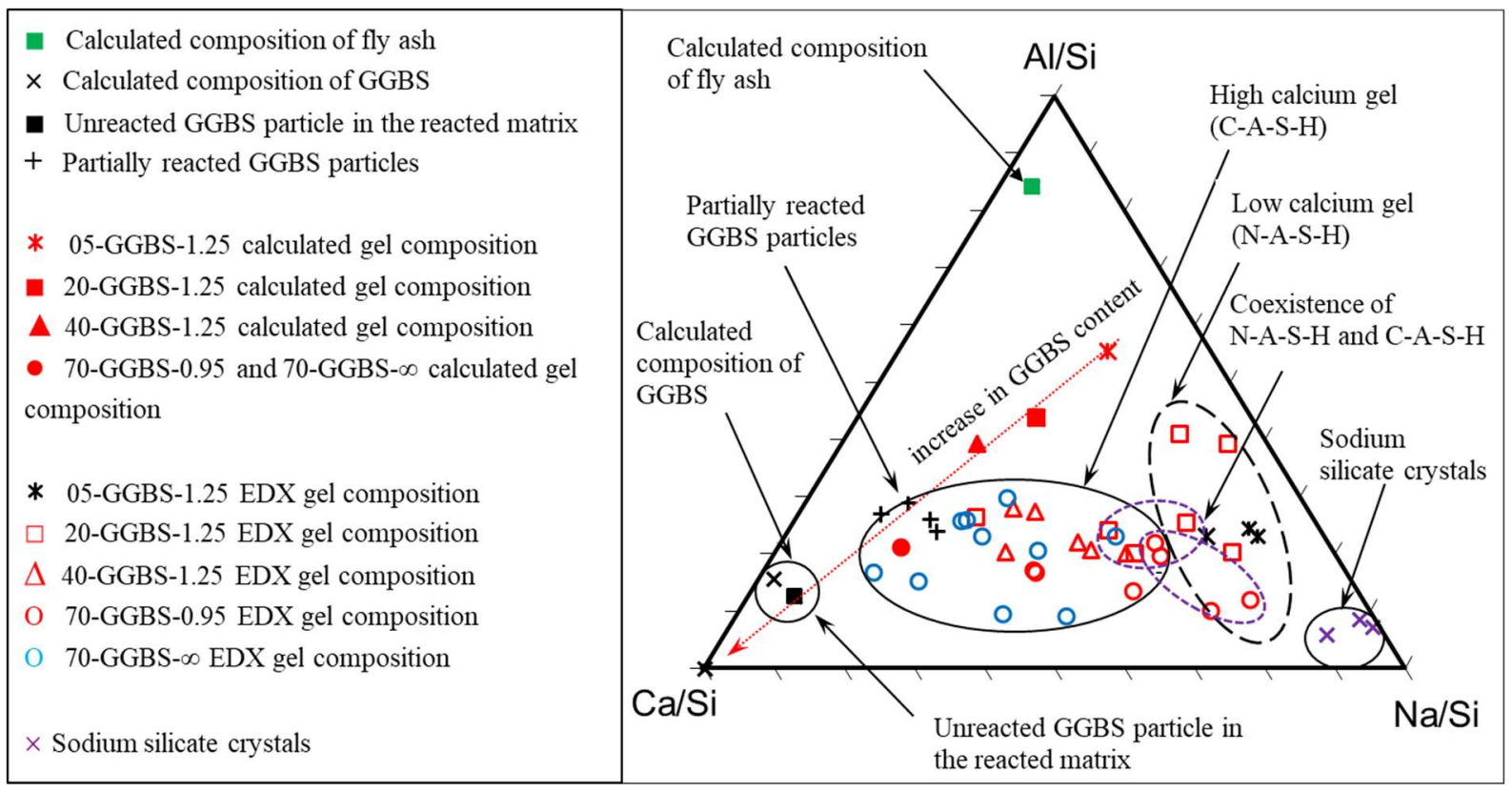

Figure 14. Pseudo-ternary diagram showing $\mathrm{Al} / \mathrm{Si}, \mathrm{Na} / \mathrm{Si}$ and $\mathrm{Ca} / \mathrm{Si}$ molar ratios for fly ash/GGBS samples.

The compressive strength was generally found to increase with the increase in $\mathrm{Ca} / \mathrm{Si}$ ratio, which is in agreement with the increase in GGBS content in the sample. The highest compressive strength was obtained at $\mathrm{Ca} / \mathrm{Si}$ of 0.6 in the sample with $70 \%$ GGBS. This increase in compressive strength with the increase in $\mathrm{Ca} / \mathrm{Si}$ ratio is presumably due to evolution of C-A-S-H binding gel with increasing GGBS content in the blend, leading to a matrix with improved mechanical properties. Similarly, Si/Al ratios generally increase with increasing GGBS content. This can be due to the more complete dissolution of $\mathrm{Si}$ and $\mathrm{Al}$ from the precursors, leading to a higher degree of crosslinking in the structure of the reaction products comprising of N-A-S-H and C-A-S-H binding gels [55]. However, sample 05-GGBS-1.25 showed lower compressive strength despite $\mathrm{Si} / \mathrm{Al}$ ratio higher than that of 20-GGBS-1.25 and 40-GGBS-1.25. The lower compressive strength obtained for 05-GGBS-1.25 can be attributed to the slow reactivity of fly ash rich samples at room temperature as previously discussed. The slower reaction rate at room temperature may have hindered the dissolution of $\mathrm{Al}$ from fly ash leading to higher $\mathrm{Si} / \mathrm{Al}$ ratio. This together with the absence of C-A-S-H binding gel led to less compact matrix and therefore lower strength.

\subsection{Significance of the results and key outcomes}

The investigation described in this paper allowed to link the mechanical behaviour of alkali activated mortars with the microstructure of the binding matrix, and contributed towards the understanding of a number of key aspects related to activation of fly ash and fly ash/GGBS based binders. The mechanisms governing the reaction of low- 
$\mathrm{Ca}$ and high-Ca binders respectively are different, as it has been reported in the literature, but the behaviour of blended systems is still under investigation $[56,57]$. The research provided insights into the following:

- $\quad$ Silicate content in the activating solution: compressive strength results suggested that the silicate content in the activating solution has a direct influence on the strength development of neat fly ash samples. Ca-rich blend showed a lower dependence on the silicate contents, allowing a reduction in the activator dosage for developing satisfactory strengths. However, it was observed that the presence of silicates influenced the type of reaction. Hydration of Ca species only (leading to very similar values of compressive strength irrespective of the alkali dosage) was observed when no silicates were added, whilst production of C-A-S-H gel was found with the use of silicates in the activating solution. This finding was confirmed by results from XRD, FTIR and TGA analyses as well as by SEM images. The absence of silicates in Ca-rich blends proved to be responsible for the formation of hydrotalcite, as shown by XRD, TGA, and FTIR analyses and discussed by others [58]. A recent publication pointed out the possible role of hydrotalcite in the immobilisation of chlorides [59], although SEM images obtained in this investigation suggested that neat $\mathrm{NaOH}$ activation for Ca-rich system resulted in poorly compacted matrix, with clear repercussions in terms of resistance to degradation attacks.

- $\quad$ Effect of calcium content in the blend: blended systems appeared to be mainly influenced by the presence of Ca-rich precursor, which allowed the hardening of samples at room temperature (i.e. $20^{\circ} \mathrm{C}$ ). Microstructural analysis indicated that the presence of GGBS resulted in the production of C-A-S-H gel in the matrix, even with as low as $20 \%$ GGBS content, and this was confirmed by both XRD and EDX analysis. The use of slag in the blend was found to be linearly related to the increase of compressive strength, whereas recent studies found that a slag content higher than 50\% led to non-significant strength contribution [60]. The chemical composition of pastes obtained through EDX and their representation in pseudo-ternary plots allowed to identify the nature of the binding gel, confirming and expanding available literature on the topics of phase diagrams and co-existence of C-A-S-H and N-A-S-H gels $[10,17,61]$. The mass loss up to $600{ }^{\circ} \mathrm{C}$, used as proxy for the hydration products, proved to be related to the compressive strength of mortars in Ca-rich samples.

- Effect of curing temperature on the reaction: the effect of the curing temperature on the reaction was investigated through isothermal calorimetry. The analysis confirmed and expanded results from recent publications $[62,63]$. The study demonstrated that the temperature has a clear effect on the rate of dissolution of $\mathrm{Si}$ and $\mathrm{Al}$ in neat fly ash samples. The cumulative heat release increased by a factor of 4 by increasing the 
curing temperature from $20^{\circ} \mathrm{C}$ to $70{ }^{\circ} \mathrm{C}$, in line with what was observed by Sun and Vollpracht [62] on neat precursors heated up to $40^{\circ} \mathrm{C}$. The catalyst effect of temperature was also observed with Ca-rich blends, i.e. the final cumulative heat release did not vary under different temperatures $\left(20^{\circ} \mathrm{C}\right.$ and $\left.70^{\circ} \mathrm{C}\right)$, but the reaction was concluded in about $1 / 3$ of the time when increasing the curing temperature from $20^{\circ} \mathrm{C}$ to $70{ }^{\circ} \mathrm{C}$. Isothermal calorimetry results confirmed the findings of Singh and Subramaniam [63] on compressive strength and EDX data of alkali activated fly ash.

\section{Conclusions}

This study focused on the effects, such as mechanical and microstructural properties, of fly ash replacement with GGBS in alkali activated mortars and pastes. The conclusions from the work reported in this paper are:

- The partial substitution of fly ash with GGBS reduced the activator dosages required for obtaining high compressive strength. This has cost and environmental benefits. Whilst neat fly ash mortar mixes (cured at $70{ }^{\circ} \mathrm{C}$ ) needed alkali modulus (AM) of 0.85 and alkali dosage $(\mathrm{M}+)$ of $11.5 \%$ for obtaining a 7 -day compressive strength in excess of $70 \mathrm{MPa}$, high GGBS content mixes gave similar strength with AM of 1.25 and $\mathrm{M}+$ of $7.5 \%$. The addition of GGBS in the mix also eliminated the need for oven curing.

- Two reaction mechanisms were identified from IC analysis. With no or low GGBS content, the exothermic reaction was mainly due to the dissolution of aluminosilicate precursor from fly ash. This reaction took place very early but required external energy (i.e., heating) for its full development. A more exothermic reaction was observed with higher GGBS contents. This was due to the hydration of calcium silicate species and formation of C-A-S-H gel. An increase in the curing temperature for high GGBS content mixes resulted in a faster reaction, whilst the volume of C-A-S-H gel produced did not change significantly.

- The increase of GGBS content in the blend allowed the formation of C-A-S-H gel which improved the matrix and thus the mechanical properties of the mortars. XRD, FTIR and TGA results confirmed the presence of C-A-S-H-like gel as a reaction product. A correlation between the amount of such gel in the matrix and the mortar compressive strength was found.

- The main reaction product in neat fly ash samples was an amorphous aluminosilicate hydrate gel with sodium in the structure (N-A-S-H). More compact and dense matrix was observed as the content of GGBS increased in the blend. C-A-S-H was the main binding gel found in formulations with $40 \%$ GGBS content or higher. XRD and EDX chemical analysis suggested the formation of C-A-S-H gel in the 
sample with as low as $20 \%$ GGBS content. Compressive strength was found to increase with the increase in $\mathrm{Ca} / \mathrm{Si}$ and $\mathrm{Si} / \mathrm{Al}$ ratios suggesting an increase in the degree of cross-linking of the reaction products and therefore more homogenous and compact matrix.

- Alkali activation of GGBS-rich mix with neat sodium hydroxide solution (i.e., no silicate in the activation) resulted in morphology, gel chemistry and reaction products different from the mix activated with a mixture of sodium hydroxide and sodium silicate solution at a fixed alkali dosage $\mathrm{M}+$ of $7.5 \%$. Micrographs showed a heterogeneous matrix with larger extent of unreacted fly ash and GGBS particles indicating poor reactivity. Hydrotalcite was also identified in this sample through TGA and XRD techniques.

\section{Acknowledgements}

This research was carried out in the framework of the SUS-CON "Sustainable, Innovative and Energy-Efficient Concrete, based on the Integration of All-Waste Materials" project, which has received funding from the European Union Seventh Framework Programme (FP7/2007-2013) under Grant Agreement No. 285463 (Call FP7-2011-NMP ENV-ENERGY-ICT-EeB). Project partner ACCIONA is gratefully acknowledged for having provided SEM images of the investigated samples.

The Authors would also like to acknowledge the Government of the Sultanate of Oman represented in the Ministry of Manpower, for funding this project by sponsoring the principal author's PhD study at Queen's University Belfast.

\section{References}

[1] J.L. Provis, Green concrete or red herring? - future of alkali-activated materials, Advances in Applied Ceramics, 113(8) (2014) 472-477.

[2] J.L. Provis, A. Palomo, C. Shi, Advances in understanding alkali-activated materials, Cement and Concrete Research, 78 (2015) 110-125.

[3] S. Kumar, R. Kumar, S.P. Mehrotra, Influence of granulated blast furnace slag on the reaction, structure and properties of fly ash based geopolymer, Journal of Materials Science, 45(3) (2009) 607-615.

[4] M.A. Smith, G. J. Osborne, Slag/fly ash cements, World Cement Technology 8, no. 6 (1977).

[5] W.C. Wang, H.Y. Wang, M.H. Lo, The fresh and engineering properties of alkali activated slag as a function of fly ash replacement and alkali concentration, Construction and Building Materials, 84 (2015) 224-229. 
[6] X. Gao, Q.L. Yu, H.J.H. Brouwers, Reaction kinetics, gel character and strength of ambient temperature cured alkali activated slag - fly ash blends, Construction and Building Materials, 80 (2015) 105-115.

[7] I. Ismail, Durability as a function of microstructure of alkali-activated slag/fly ash binders, Doctoral dissertation, University of Melbourne, Australia, 2013.

[8] P.S. Deb, P. Nath, P.K. Sarker, The effects of ground granulated blast-furnace slag blending with fly ash and activator content on the workability and strength properties of geopolymer concrete cured at ambient temperature, Materials and Design, 62 (2014) 32-39.

[9] P. Nath, P.K. Sarker, Effect of ggbfs on setting, workability and early strength properties of fly ash geopolymer concrete cured in ambient condition, Construction and Building Materials, 66 (2014) $163-171$.

[10] I. Ismail, S.A. Bernal, J.L. Provis, R. San Nicolas, S. Hamdan, J.S. Van Deventer, Modification of phase evolution in alkali-activated blast furnace slag by the incorporation of fly ash, Cement and Concrete Composites, 45 (2014) 125-135.

[11] ASTM C618, Standard specification for coal fly ash and raw or calcined natural pozzolan for use in concrete, ASTM International (2008).

[12] British Standards Institution, Fly ash for concrete. Definition, specifications and conformity criteria, BS EN 450-1 (2012)

[13] R. Vinai, A. Rafeet, M.N. Soutsos, W. Sha, The role of water content and paste proportion on physicomechanical properties of alkali activated fly ash-ggbs concrete, Journal of Sustainable Metallurgy, 2(1) (2016) $51-61$.

[14] M.N. Soutsos, A.P. Boyle, R. Vinai, A. Hadjierakleous, S.J. Barnett, Factors influencing the compressive strength of fly ash based geopolymers, Construction and Building Materials, 110 (2016) 355-368.

[15] J.G. Jang, N.K. Lee, H.K. Lee, Fresh and hardened properties of alkali-activated fly ash/slag pastes with superplasticizers, Construction and Building Materials, 50 (2014) 169-176.

[16] E.I. Diaz, E.N. Allouche, S. Eklund, Factors affecting the suitability of fly ash as source material for geopolymers, Fuel, 89(5) (2010) 992-996.

[17] C.K. Yip, G.C. Lukey, J.S.J. Van Deventer, The coexistence of geopolymeric gel and calcium silicate hydrate at the early stage of alkaline activation, Cement and Concrete Research, 35, (2005) 1688-1697.

[18] A. Palomo, M.W. Grutzeck, M.T. Blanco, Alkali-activated fly ashes: a cement for the future, Cement and Concrete Research, 29(8) (1999) 1323-1329. 
[19] P. Duxson, J.L. Provis, G.C. Lukey, S.W. Mallicoat, W.M. Kriven, J.S. Van Deventer, Understanding the relationship between geopolymer composition, microstructure and mechanical properties, Colloids and Surfaces A: Physicochemical and Engineering Aspects, 269(1) (2005) 47-58.

[20] C. Lampris, R. Lupo, C. R. Cheeseman, Geopolymerisation of silt generated from construction and demolition waste washing plants, Waste Management, 29(1) (2009) 368-373.

[21] M. Sisol, M. Kolesarova, I. Krincka, F. Michalikova, M. Prascakova, The evaluation of geopolymer properties prepared by alkali activation of black coal ashes with high content of loss on ignition, Acta Montanistica Slovaca, 15, (2010) 277-282.

[22] Z. Xie, Y. Xi, Hardening mechanisms of an alkaline-activated class F fly ash, Cement and Concrete Research, 31(9) (2001) 1245-1249.

[23] A.A. Adam, Strength and durability properties of alkali activated slag and fly ash-based geopolymer concrete, Doctoral dissertation, RMIT University Melbourne, Australia (2009).

[24] A. Hajimohammadi, J.L. Provis, J.S.J van Deventer, The effect of silica availability on the mechanism of geopolymerisation, Cement and Concrete Research, 41(3) (2011) 210-216.

[25] J. Chang, A study on the setting characteristics of sodium silicate-activated slag pastes, Cement and Concrete Research, 33(7) (2003) 1005-1011.

[26] H.S. Pietersen, A.L. Fraay, J.M. Bijen, Reactivity of fly ash at high pH, In MRS Proceedings Vol. 178, (1989) p. 139 Cambridge University Press.

[27] S.D. Wang, K.L. Scrivener, P.L. Pratt, Factors affecting the strength of alkali-activated slag. Cement and Concrete Research, 24(6) (1994) 1033-1043.

[28] M. Chi, R. Huang, Binding mechanism and properties of alkali-activated fly ash/slag mortars, Construction and Building Materials, 40 (2013) 291-298.

[29] H.F.W. Taylor H, Cement Chemistry $2^{\text {nd }}$ ed., Thomas Telford Publishing (1997).

[30] J. Escalante Garcia, K. Campos-Venegas, A. Gorokhovsky, A. Fernandez, Cementitious composites of pulverised fuel ash and blast furnace slag activated by sodium silicate: effect of $\mathrm{Na}_{2} \mathrm{O}$ concentration and modulus, Advances in Applied Ceramics, 105(4) (2006) 201-208.

[31] S. Chithiraputhiran, N. Neithalath, Isothermal reaction kinetics and temperature dependence of alkali activation of slag, fly ash and their blends, Construction and Building Materials, 45 (2013) 233-242.

[32] C. Shi, R.L. Day, Some factors affecting early hydration of alkali-slag cements, Cement and Concrete Research, 26(3) (1996) 439-447. 
[33] C. Shi, P.V. Krivenko, D. Roy, Alkali-Activated Cements and Concretes, $1^{\text {st }}$ ed. Taylor and Francis, New York, NY, 2006.

[34] S.A. Bernal, J.L. Provis, V. Rose, R.M. De Gutierrez, Evolution of binder structure in sodium silicateactivated slag-metakaolin blends, Cement and Concrete Composites, 33(1) (2011) 46-54.

[35] C. Shi, R. Day, A calorimetric study of early hydration of alkali-slag cements, Cement and Concrete Research, 25(6) (1995) 1333-1346.

[36] A. Fernández-Jiménez, F. Puertas, Effect of activator mix on the hydration and strength behaviour of alkaliactivated slag cements, Advances in Cement Research, 15(3) (2003) 129-136.

[37] S.D. Wang, K.L. Scrivener, Hydration products of alkali activated slag cement, Cement and Concrete Research, 25(3) (1995) 561-571.

[38] S.A. Bernal, J.L. Provis, B. Walkley, R. San Nicolas, J.D. Gehman, D.G. Brice, D. G., J.S. van Deventer, Gel nanostructure in alkali-activated binders based on slag and fly ash, and effects of accelerated carbonation, Cement and Concrete Research, 53, (2013) 127-144.

[39] J. Escalante-García, A.F. Fuentes, A. Gorokhovsky, P.E. Fraire-Luna, G. Mendoza-Suarez, Hydration products and reactivity of blast furnace slag activated by various alkalis, Journal of the American Ceramic Society, 86(12), (2003) 2148-2153.

[40] B. Lothenbach, A. Gruskovnjak, Hydration of alkali-activated slag : thermodynamic modelling, Advances in Cement Research, 19(2) (2007) 81-92.

[41] M.B. Haha, B. Lothenbach, G. Le Saout, F. Winnefeld, Influence of slag chemistry on the hydration of alkali-activated blast-furnace slag — Part I: Effect of MgO, Cement and Concrete Research, 41(9) (2011) 955963.

[42] M. Asadi, A. Nemati, R. Naghizadeh, K. Arzani, J. Fahim, Effect of temperature and activator molar of $\mathrm{Na}_{2} \mathrm{O}$ to $\mathrm{SiO}_{2}$ in the process of synthesis and microstructure of cement geopolymer, Advanced Materials and Processing, 1(3) (2013) 3-10.

[43] A. Fernández-Jiménez, A. Palomo, Composition and microstructure of alkali activated fly ash binder: Effect of the activator, Cement and Concrete Research, 35(10) (2005) 1984-1992.

[44] M. Criado, A. Fernández-Jiménez, A. Palomo, Alkali activation of fly ash: Effect of the $\mathrm{SiO}_{2} / \mathrm{Na}_{2} \mathrm{O}$ ratio. Part I: FTIR study, Microporous and Mesoporous Materials, 106 (2007) 180-191. 
[45] E.D. Rodríguez, S.A. Bernal, J.L. Provis, J. Paya, J.M. Monzo, M.V. Borrachero, Effect of nanosilicabased activators on the performance of an alkali-activated fly ash binder, Cement and Concrete Composites, 35(1) (2013) 1-11.

[46] J.P. Brady, An examination of the applicability of hydrotalcite for removing oxalate anions from Bayer process solutions, Masters by research thesis, Queensland University of Technology, Australia, (2011).

[47] L.T. Zhuravlev, The surface chemistry of amorphous silica. Zhuravlev model, Colloids and Surfaces A: Physicochemical and Engineering Aspects, 173(1) (2000) 1-38.

[48] M.N. Soutsos, R. Vinai, A. Rafeet, Effect of alkali dosage and modulus on strength development and microstructure of alkali-activated binders, In $14^{\text {th }}$ International Congress on the Chemistry of Cement, Beijing, China (2015).

[49] I.G. Richardson, A.R. Brough, G.W. Groves, C.M. Dobson, The characterization of hardened alkaliactivated blast-furnace slag pastes and the nature of the calcium silicate hydrate (C-S-H) phase, Cement and Concrete Research, 24(5) (1994) 813-829.

[50] I.G. Richardson, The nature of C-S-H in hardened cements, Cement and Concrete Research, 29(8) (1999) 1131-1147.

[51] N. Marjanović, M. Komljenović, Z. Baščarević, V. Nikolić, R. Petrović, Physical-mechanical and microstructural properties of alkali-activated fly ash-blast furnace slag blends, Ceramics International, 41(1), (2015) 1421-1435.

[52] J.L. Provis, R.J. Myers, C.E. White, V. Rose, J.S. van Deventer, X-ray microtomography shows pore structure and tortuosity in alkali-activated binders, Cement and Concrete Research, 42(6) (2012) 855-864. [53] R.R. Lloyd, J.L. Provis, J.S.J. Van Deventer, Microscopy and microanalysis of inorganic polymer cements. 1: Remnant fly ash particles, Journal of Materials Science, 44(2) (2009) 608-619.

[54] I. Garcia-Lodeiro, A. Palomo, A. Fernández-Jiménez, D.E. MacPhee, Compatibility studies between N-A$\mathrm{S}-\mathrm{H}$ and C-A-S-H gels. Study in the ternary diagram $\mathrm{Na}_{2} \mathrm{O}-\mathrm{CaO}-\mathrm{Al}_{2} \mathrm{O}_{3}-\mathrm{SiO}_{2}-\mathrm{H}_{2} \mathrm{O}$, Cement and Concrete Research, 41(9) (2011) 923-931.

[55] F. Puertas, A. Fernández-Jiménez, Mineralogical and microstructural characterisation of alkali-activated fly ash/slag pastes, Cement and Concrete composites, 25 (2003) 287-292.

[56] X. Zhao, C. Liu, L. Zuo, L. Wang, Q. Zhu, M. Wang, Investigation into the effect of calcium on the existence form of geopolymerized gel product of fly ash based geopolymers, Cement and Concrete Composites, in press, https://doi.org/10.1016/j.cemconcomp.2018.11.019 (2018). 
[57] G. Fang, W.K. Ho, W. Tu, M. Zhang, Workability and mechanical properties of alkali-activated fly ashslag concrete cured at ambient temperature. Construction and Building Materials, 172 (2018) 476-87.

[58] K. Gong, C.E. White, Impact of chemical variability of ground granulated blast-furnace slag on the phase formation in alkali-activated slag pastes, Cement and Concrete Research, 89 (2016) 310-319.

[59] X. Ke, S.A. Bernal, J.L. Provis, Uptake of chloride and carbonate by Mg-Al and Ca-Al layered double hydroxides in simulated pore solutions of alkali-activated slag cement, Cement and Concrete Research, 100 (2017) 1-13.

[60] M.A. Yazdi, M. Liebscher, S. Hempel, J. Yang, V. Mechtcherine, Correlation of microstructural and mechanical properties of geopolymers produced from fly ash and slag at room temperature, Construction and Building Materials, 191 (2018) 330-341.

[61] R.J. Myers, S.A. Bernal, J.L. Provis, Phase diagrams for alkali-activated slag binders, Cement and Concrete Research, 95 (2017) 30-38.

[62] Z. Sun, A. Vollpracht, Isothermal calorimetry and in-situ XRD study of the $\mathrm{NaOH}$ activated fly ash, metakaolin and slag, Cement and Concrete Research, 103 (2018) 110-122.

[63] G.B. Singh, K.V. Subramaniam, Influence of processing temperature on the reaction product and strength gain in alkali-activated fly ash, Cement and Concrete Composites 95 (2019) 10-18.

[64] N.V. Scarlett, I.C. Madsen, Quantification of phases with partial or no known crystal structures, Powder Diffraction, 21(4) (2006) 278-284.

[65] G.B.Singh, K.V. Subramaniam, Evaluation of sodium content and sodium hydroxide molarity on compressive strength of alkali activated low-calcium fly ash, Cement and Concrete Composites, 81(2017) 122 132.

[66] J.L. Provis, J.S. Van Deventer (editors), Alkali activated materials: state-of-the-art report, RILEM TC 224AAM. Springer Science \& Business Media (2013). 


\section{Appendix A}

Table A1. Mix proportions for mortar production batch. Asterisk denotes samples prepared with $\mathrm{NaOH}$ solution at $40 \%$ conc.

\begin{tabular}{|c|c|c|c|c|c|c|}
\hline Label & $\begin{array}{l}\text { Fly ash } \\
\text { (g) }\end{array}$ & $\begin{array}{l}\text { GGBS } \\
(\mathrm{g})\end{array}$ & $\begin{array}{c}\text { NaOH solution @ } \\
\text { 30\% conc. (g) }\end{array}$ & $\begin{array}{l}\text { Sodium silicate } \\
\text { solution (g) }\end{array}$ & $\begin{array}{l}\text { Water } \\
\text { (g) }\end{array}$ & $\begin{array}{c}\text { Sand } \\
\text { (g) }\end{array}$ \\
\hline FA-7.5-inf & 500 & 0 & 161 & 0 & 86 & 1375 \\
\hline FA-7.5-30 & 500 & 0 & 159 & 5 & 85 & 1375 \\
\hline FA-7.5-5 & 500 & 0 & 145 & 29 & 82 & 1375 \\
\hline FA-7.5-1.5 & 500 & 0 & 107 & 98 & 73 & 1375 \\
\hline FA-7.5-1.35 & 500 & 0 & 101 & 109 & 71 & 1375 \\
\hline FA-7.5-1.25 & 500 & 0 & 97 & 118 & 70 & 1375 \\
\hline FA-7.5-1.15 & 500 & 0 & 91 & 128 & 68 & 1375 \\
\hline FA-7.5-1.05 & 500 & 0 & 84 & 140 & 67 & 1375 \\
\hline FA-7.5-0.95 & 500 & 0 & 76 & 155 & 65 & 1375 \\
\hline FA-7.5-0.85 & 500 & 0 & 66 & 173 & 62 & 1375 \\
\hline FA-7.5-0.75 & 500 & 0 & 53 & 196 & 59 & 1375 \\
\hline FA-7.5-0.50 & 500 & 0 & 0 & 294 & 45 & 1375 \\
\hline FA-8.5-inf & 500 & 0 & 183 & 0 & 73 & 1375 \\
\hline FA-8.5-30 & 500 & 0 & 180 & 6 & 72 & 1375 \\
\hline FA-8.5-5 & 500 & 0 & 164 & 33 & 68 & 1375 \\
\hline FA-8.5-1.5 & 500 & 0 & 122 & 111 & 58 & 1375 \\
\hline FA-8.5-1.35 & 500 & 0 & 115 & 123 & 56 & 1375 \\
\hline FA-8.5-1.25 & 500 & 0 & 109 & 133 & 54 & 1375 \\
\hline FA-8.5-1.15 & 500 & 0 & 103 & 145 & 53 & 1375 \\
\hline FA-8.5-1.05 & 500 & 0 & 95 & 159 & 51 & 1375 \\
\hline FA-8.5-0.95 & 500 & 0 & 86 & 175 & 49 & 1375 \\
\hline FA-8.5-0.85 & 500 & 0 & 75 & 196 & 46 & 1375 \\
\hline FA-8.5-0.75 & 500 & 0 & 60 & 222 & 42 & 1375 \\
\hline FA-8.5-0.50 & 500 & 0 & 0 & 333 & 27 & 1375 \\
\hline FA-9.5-inf & 500 & 0 & 204 & 0 & 60 & 1375 \\
\hline FA-9.5-30 & 500 & 0 & 201 & 6 & 59 & 1375 \\
\hline FA-9.5-5 & 500 & 0 & 184 & 37 & 54 & 1375 \\
\hline FA-9.5-1.25 & 500 & 0 & 122 & 149 & 39 & 1375 \\
\hline FA-9.5-1.15 & 500 & 0 & 115 & 162 & 37 & 1375 \\
\hline FA-9.5-1.05 & 500 & 0 & 107 & 177 & 35 & 1375 \\
\hline FA-9.5-0.95 & 500 & 0 & 96 & 196 & 33 & 1375 \\
\hline FA-9.5-0.85 & 500 & 0 & 84 & 219 & 29 & 1375 \\
\hline FA-9.5-0.75 & 500 & 0 & 68 & 248 & 25 & 1375 \\
\hline FA-9.5-0.50 & 500 & 0 & 0 & 373 & 8 & 1375 \\
\hline FA-10.5-inf & 500 & 0 & 226 & 0 & 46 & 1375 \\
\hline FA-10.5-30 & 500 & 0 & 222 & 7 & 45 & 1375 \\
\hline FA-10.5-5 & 500 & 0 & 203 & 41 & 41 & 1375 \\
\hline FA-10.5-1.05 & 500 & 0 & 118 & 196 & 19 & 1375 \\
\hline FA-10.5-0.95 & 500 & 0 & 106 & 217 & 17 & 1375 \\
\hline
\end{tabular}




\begin{tabular}{lllllll} 
FA-10.5-0.85 & 500 & 0 & 92 & 242 & 13 & 1375 \\
FA-10.5-0.75 & 500 & 0 & 75 & 275 & 9 & 1375 \\
FA-10.5-0.50 & 500 & 0 & 0 & 412 & 0 & 1375 \\
FA-11.5-1.05 & 500 & 0 & 129 & 215 & 4 & 1375 \\
FA-11.5-0.95 & 500 & 0 & 117 & 237 & 1 & 1375 \\
FA-11.5-0.85 & 500 & 0 & 101 & 265 & 0 & 1375 \\
FA-11.5-0.75 & 500 & 0 & 82 & 301 & 0 & 1375 \\
FA-12.5-1.05* & 500 & 0 & 105 & 233 & 23 & 1375 \\
FA-12.5-0.95* & 500 & 0 & 95 & 258 & 16 & 1375 \\
FA-12.5-0.85* & 500 & 0 & 83 & 288 & 8 & 1375 \\
FA-12.5-0.75* & 500 & 0 & 67 & 327 & 0 & 1375 \\
FA-13.5-0.95* & 500 & 0 & 103 & 279 & 3 & 1375 \\
FA-13.5-0.85* & 500 & 0 & 89 & 311 & 0 & 1375 \\
FA-13.5-0.75* & 500 & 0 & 72 & 353 & 0 & 1375 \\
\hline
\end{tabular}


Table A2. Mix proportions for 1 litre of mortar. Asterisk denotes samples prepared with $\mathrm{NaOH}$ solution at $40 \%$ conc.

\begin{tabular}{|c|c|c|c|c|c|c|}
\hline Label & $\begin{array}{c}\text { Fly ash } \\
\text { (g) }\end{array}$ & $\begin{array}{l}\text { GGBS } \\
(\mathrm{g})\end{array}$ & $\begin{array}{c}\mathrm{NaOH} \text { solution } @ \\
30 \% \text { conc. }(\mathrm{g})\end{array}$ & $\begin{array}{l}\text { Sodium silicate } \\
\text { solution (g) }\end{array}$ & $\begin{array}{l}\text { Water } \\
\text { (g) }\end{array}$ & $\begin{array}{c}\text { Sand } \\
\text { (g) }\end{array}$ \\
\hline FA-7.5-inf & 541 & 0 & 174 & 0 & 93 & 1486 \\
\hline FA-7.5-30 & 540 & 0 & 171 & 5 & 92 & 1485 \\
\hline FA-7.5-5 & 538 & 0 & 156 & 32 & 88 & 1479 \\
\hline FA-7.5-1.5 & 531 & 0 & 114 & 104 & 77 & 1461 \\
\hline FA-7.5-1.35 & 530 & 0 & 107 & 116 & 75 & 1458 \\
\hline FA-7.5-1.25 & 530 & 0 & 102 & 125 & 74 & 1456 \\
\hline FA-7.5-1.15 & 529 & 0 & 96 & 135 & 72 & 1454 \\
\hline FA-7.5-1.05 & 528 & 0 & 89 & 148 & 70 & 1451 \\
\hline FA-7.5-0.95 & 526 & 0 & 80 & 163 & 68 & 1447 \\
\hline FA-7.5-0.85 & 525 & 0 & 69 & 182 & 65 & 1442 \\
\hline FA-7.5-0.75 & 522 & 0 & 56 & 205 & 62 & 1437 \\
\hline FA-7.5-0.50 & 514 & 0 & 0 & 302 & 46 & 1413 \\
\hline FA-8.5-inf & 539 & 0 & 197 & 0 & 78 & 1482 \\
\hline FA-8.5-30 & 538 & 0 & 193 & 6 & 78 & 1480 \\
\hline FA-8.5-5 & 536 & 0 & 176 & 36 & 73 & 1473 \\
\hline FA-8.5-1.5 & 528 & 0 & 129 & 117 & 61 & 1453 \\
\hline FA-8.5-1.35 & 527 & 0 & 121 & 130 & 59 & 1450 \\
\hline FA-8.5-1.25 & 526 & 0 & 115 & 140 & 57 & 1448 \\
\hline FA-8.5-1.15 & 525 & 0 & 108 & 152 & 56 & 1445 \\
\hline FA-8.5-1.05 & 524 & 0 & 100 & 166 & 53 & 1442 \\
\hline FA-8.5-0.95 & 523 & 0 & 90 & 183 & 51 & 1437 \\
\hline FA-8.5-0.85 & 521 & 0 & 78 & 204 & 48 & 1432 \\
\hline FA-8.5-0.75 & 519 & 0 & 63 & 230 & 44 & 1426 \\
\hline FA-8.5-0.50 & 509 & 0 & 0 & 339 & 27 & 1400 \\
\hline FA-9.5-inf & 537 & 0 & 219 & 0 & 64 & 1477 \\
\hline FA-9.5-30 & 537 & 0 & 216 & 7 & 63 & 1475 \\
\hline FA-9.5-5 & 534 & 0 & 196 & 40 & 58 & 1467 \\
\hline FA-9.5-1.25 & 523 & 0 & 128 & 156 & 41 & 1439 \\
\hline FA-9.5-1.15 & 522 & 0 & 120 & 169 & 39 & 1436 \\
\hline FA-9.5-1.05 & 521 & 0 & 111 & 185 & 37 & 1432 \\
\hline FA-9.5-0.95 & 519 & 0 & 100 & 204 & 34 & 1428 \\
\hline FA-9.5-0.85 & 517 & 0 & 87 & 227 & 30 & 1422 \\
\hline FA-9.5-0.75 & 515 & 0 & 70 & 256 & 26 & 1415 \\
\hline FA-9.5-0.50 & 504 & 0 & 0 & 376 & 8 & 1386 \\
\hline FA-10.5-inf & 535 & 0 & 242 & 0 & 50 & 1472 \\
\hline FA-10.5-30 & 535 & 0 & 237 & 7 & 49 & 1471 \\
\hline FA-10.5-5 & 532 & 0 & 216 & 44 & 43 & 1462 \\
\hline FA-10.5-1.05 & 518 & 0 & 122 & 203 & 20 & 1424 \\
\hline FA-10.5-0.95 & 516 & 0 & 110 & 224 & 17 & 1419 \\
\hline FA-10.5-0.85 & 514 & 0 & 95 & 249 & 13 & 1413 \\
\hline FA-10.5-0.75 & 511 & 0 & 76 & 280 & 9 & 1405 \\
\hline
\end{tabular}




\begin{tabular}{lllllll} 
FA-10.5-0.50 & 494 & 0 & 0 & 407 & 0 & 1359 \\
FA-11.5-1.05 & 514 & 0 & 133 & 221 & 4 & 1415 \\
FA-11.5-0.95 & 513 & 0 & 120 & 243 & 1 & 1409 \\
FA-11.5-0.85 & 508 & 0 & 103 & 270 & 0 & 1398 \\
FA-11.5-0.75 & 503 & 0 & 82 & 302 & 0 & 1383 \\
FA-12.5-1.05* & 507 & 0 & 107 & 237 & 23 & 1394 \\
FA-12.5-0.95* & 505 & 0 & 96 & 261 & 16 & 1389 \\
FA-12.5-0.85* & 503 & 0 & 83 & 290 & 8 & 1384 \\
FA-12.5-0.75* & 499 & 0 & 67 & 326 & 0 & 1373 \\
FA-13.5-0.95* & 502 & 0 & 103 & 280 & 3 & 1380 \\
FA-13.5-0.85* & 496 & 0 & 89 & 309 & 0 & 1365 \\
FA-13.5-0.75* & 488 & 0 & 70 & 345 & 0 & 1343 \\
\hline
\end{tabular}


Table A3. Mix proportions for mortar production batch.

\begin{tabular}{|c|c|c|c|c|c|c|}
\hline Label & Fly ash (g) & GGBS (g) & $\begin{array}{l}\mathrm{NaOH} \text { solution @ } \\
\mathbf{3 0 \%} \text { conc. (g) }\end{array}$ & $\begin{array}{l}\text { Sodium silicate } \\
\text { solution (g) }\end{array}$ & Water (g) & Sand $(g)$ \\
\hline FA-G-4.5-inf & 150 & 350 & 97 & 0 & 141 & 1375 \\
\hline FA-G-4.5-1.25 & 150 & 350 & 58 & 71 & 132 & 1375 \\
\hline FA-G-4.5-1.15 & 150 & 350 & 55 & 77 & 131 & 1375 \\
\hline FA-G-4.5-0.95 & 150 & 350 & 46 & 93 & 129 & 1375 \\
\hline FA-G-4.5-0.75 & 150 & 350 & 32 & 118 & 126 & 1375 \\
\hline FA-G-6.0-inf & 150 & 350 & 129 & 0 & 122 & 1375 \\
\hline FA-G-6.0-1.25 & 150 & 350 & 77 & 94 & 109 & 1375 \\
\hline FA-G-6.0-1.15 & 150 & 350 & 73 & 102 & 108 & 1375 \\
\hline FA-G-6.0-0.95 & 150 & 350 & 61 & 124 & 106 & 1375 \\
\hline FA-G-6.0-0.75 & 150 & 350 & 43 & 157 & 101 & 1375 \\
\hline FA-G-7.5-inf & 150 & 350 & 161 & 0 & 102 & 1375 \\
\hline FA-G-7.5-1.25 & 150 & 350 & 97 & 118 & 87 & 1375 \\
\hline FA-G-7.5-1.15 & 150 & 350 & 0 & 128 & 149 & 1375 \\
\hline FA-G-7.5-0.95 & 150 & 350 & 76 & 155 & 82 & 1375 \\
\hline FA-G-7.5-0.75 & 150 & 350 & 53 & 196 & 77 & 1375 \\
\hline FA-G-8.5-inf & 150 & 350 & 183 & 0 & 89 & 1375 \\
\hline FA-G-8.5-1.25 & 150 & 350 & 109 & 133 & 72 & 1375 \\
\hline FA-G-8.5-1.15 & 150 & 350 & 103 & 145 & 70 & 1375 \\
\hline FA-G-8.5-0.95 & 150 & 350 & 86 & 175 & 66 & 1375 \\
\hline FA-G-8.5-0.75 & 150 & 350 & 60 & 222 & 60 & 1375 \\
\hline FA-G-10.5-inf & 150 & 350 & 226 & 0 & 63 & 1375 \\
\hline FA-G-10.5-1.25 & 150 & 350 & 135 & 165 & 42 & 1375 \\
\hline FA-G-10.5-1.15 & 150 & 350 & 0 & 179 & 129 & 1375 \\
\hline FA-G-10.5-0.95 & 150 & 350 & 106 & 217 & 35 & 1375 \\
\hline FA-G-10.5-0.75 & 150 & 350 & 75 & 275 & 27 & 1375 \\
\hline
\end{tabular}


Table A4. Mix proportions for 1 litre of mortar.

\begin{tabular}{|c|c|c|c|c|c|c|}
\hline Label & Fly ash (g) & GGBS (g) & $\begin{array}{l}\mathrm{NaOH} \text { solution } @ \\
30 \% \text { conc. }(\mathrm{g})\end{array}$ & $\begin{array}{c}\text { Sodium silicate } \\
\text { solution (g) }\end{array}$ & Water (g) & Sand $(g)$ \\
\hline FA-G-4.5-inf & 165 & 386 & 107 & 0 & 156 & 1516 \\
\hline FA-G-4.5-1.25 & 163 & 381 & 63 & 77 & 144 & 1496 \\
\hline FA-G-4.5-1.15 & 163 & 380 & 59 & 83 & 143 & 1494 \\
\hline FA-G-4.5-0.95 & 163 & 379 & 49 & 101 & 140 & 1490 \\
\hline FA-G-4.5-0.75 & 162 & 378 & 35 & 127 & 136 & 1483 \\
\hline FA-G-6.0-inf & 165 & 384 & 142 & 0 & 133 & 1508 \\
\hline FA-G-6.0-1.25 & 162 & 377 & 83 & 101 & 118 & 1482 \\
\hline FA-G-6.0-1.15 & 161 & 377 & 78 & 110 & 117 & 1480 \\
\hline FA-G-6.0-0.95 & 161 & 375 & 65 & 133 & 113 & 1474 \\
\hline FA-G-6.0-0.75 & 160 & 373 & 45 & 167 & 108 & 1465 \\
\hline FA-G-7.5-inf & 164 & 382 & 176 & 0 & 111 & 1500 \\
\hline FA-G-7.5-1.25 & 160 & 374 & 103 & 126 & 93 & 1468 \\
\hline FA-G-7.5-1.15 & 161 & 375 & 0 & 137 & 160 & 1473 \\
\hline FA-G-7.5-0.95 & 159 & 371 & 81 & 164 & 87 & 1458 \\
\hline FA-G-7.5-0.75 & 158 & 368 & 56 & 206 & 81 & 1448 \\
\hline FA-G-8.5-inf & 163 & 381 & 199 & 0 & 97 & 1495 \\
\hline FA-G-8.5-1.25 & 159 & 371 & 116 & 142 & 76 & 1459 \\
\hline FA-G-8.5-1.15 & 159 & 371 & 109 & 153 & 74 & 1456 \\
\hline FA-G-8.5-0.95 & 158 & 369 & 91 & 185 & 70 & 1448 \\
\hline FA-G-8.5-0.75 & 157 & 366 & 63 & 232 & 63 & 1436 \\
\hline FA-G-10.5-inf & 162 & 378 & 244 & 0 & 68 & 1485 \\
\hline FA-G-10.5-1.25 & 157 & 367 & 142 & 173 & 44 & 1442 \\
\hline FA-G-10.5-1.15 & 158 & 369 & 0 & 189 & 136 & 1448 \\
\hline FA-G-10.5-0.95 & 156 & 364 & 111 & 225 & 36 & 1428 \\
\hline FA-G-10.5-0.75 & 154 & 360 & 77 & 282 & 28 & 1414 \\
\hline
\end{tabular}

